\title{
Análisis de la jurisprudencia electoral chilena*
}

\author{
Case law analysis of electoral chilean \\ Análise de jurisprudência eleitoral chileno
}

Revista LOGOS CIENCIA \& TECNOLOGÍA ISSN 2145-549X,

Vol 3. No. 2, Enero - Junio, 2012, pp. 128-167

\section{Resumen}

A partir de la reinstauración de la democracia en Chile en el año de 1989, se reestableció el funcionamiento del Tribunal Calificador de Elecciones. Este trabajo presenta un análisis de la producción jurisdiccional de este órgano jurisdiccional desde 1989 hasta 2007, para descubrir cómo funda y motiva sus fallos, los requisitos para acceder a la justicia electoral, entre otros rubros.

Palabras claves: Jurisprudencia, justicia electoral, tribunal electoral.

Fecha de Recepción: 15 de Agosto de 2011.

Fecha de Aceptación: 27 de septiembre de 2011.

* Este articulo es producto de la Tesis Doctoral del autor denominada "Dos modelos de justicia electoral: Los Tribunales electorales de Chile y México".

** Licenciado en Derecho por la Universidad Autónoma de México, con Estudios de Postgrado en la Universidad de Chile. Su contacto es cmr268@yahoo.com

\begin{abstract}
From the restoration of the democracy in Chile in the year of 1988, it was re-established the functioning of the Electoral Court. This work presents an analysis of the jurisdictional production of this Court from 1989 until 2007, to discover how it elaborates his resolutions, the requirements to accede to the electoral justice, between other items.
\end{abstract}

Key words: Jurisprudence, electoral justice, electoral court.

\section{Resumo}

Desde a restauração da democracia no Chile em 1989, restaurou o funcionamento do Tribunal Eleitoral. Este trabalho apresenta uma análise da produção dessa corte ou tribunal 1989-2007 para descobrir como cobrir e motiva suas decisões, os requisitos de acesso à Justiça Eleitoral, entre outros itens.

Palavras chave Jurisprudência, a justiça eleitoral, tribunal eleitoral. 


\section{INTRODUCCIÓN}

A partir del restablecimiento de la democracia en Chile en 1989, se volvió a activar la participación ciudadana y la actuación de los partidos políticos. Esto fue un largo proceso que comenzó con el plebiscito de 1980 , que tenía por objeto la validación de la Constitución impuesta por la dictadura de Augusto Pinochet y las sentencias del Tribunal Constitucional (que juzgó la legalidad de las leyes electorales de 1988). Estos fueron los elementos claves que permitieron la debida y oportuna reinstauración de las autoridades electorales. ${ }^{1}$

De esta manera, el sistema electoral se conformó a partir de un modelo mixto, o sea, las tareas electorales se dividen en dos instituciones públicas e independientes, que realizan funciones administrativas $y$ jurisdiccionales. Las primeras son responsables del proceso electoral principalmente, este órgano es denominado Servicio Electoral (SE o SERVEL). Y las cuestiones de inconformidad e impugnaciones electorales son resueltas por un órgano judicial autónomo e imparcial, el Tribunal Calificador de Elecciones (TCE o TRICEL).

Este artículo presenta un análisis de la jurisprudencia electoral chilena a partir de 1989 hasta el año 2007, concentrándonos en la manera que ha sentenciado y cómo ha protegido el TCE los derechos sustantivos y procesales de los justiciables y cómo han calificado los comicios impugnados.

Por ello decidí clasificar este tema en dos grandes rubros: 1) Elecciones (impugnación de candidaturas, solicitud de nuevos escrutinios, inconformidades de los resultados electorales, entre otros) y 2) las apelaciones de los partidos políticos, en materias como resoluciones del director del Servicio Electoral (i.e. gasto electoral) o por la inconformidad por el tiempo asignado por el Consejo Nacional de Televisión (CNTV), entre otras. Otra de las grandes responsabilidades del sistema jurisdiccional electoral chileno

\footnotetext{
* Universidad de Chile.

Sentencia número 60 de 1988.
}

es la facultad legal para destituir a las autoridades municipales por el incumplimiento de sus funciones. ${ }^{2}$ Sin embargo, en este trabajo no analizaremos el tema de la remoción de autoridades edilicias, por ser un tema que sale de la esfera de lo electoral, hablando en sentido estricto. ${ }^{3}$

Comenzaremos presentando la naturaleza e importancia de la jurisprudencia en materia electoral, para presentarla en el contexto chileno.

El origen del término "jurisprudencia". Este concepto deriva de las raíces latinas jus y prudentia; Prudencia de lo justo. ${ }^{4}$

Atendiendo a su significado gramatical, la Real Academia de la Lengua (RAE) define a la jurisprudencia como: "la norma de juicio que suple omisiones de la ley, y que se funda en las prácticas seguidas en casos iguales o análogos". También, se habla de ella como: "la costumbre que impera en los tribunales".

La jurisprudencia es conocida como la interpretación de las normas legales elaborada por los jueces y los tribunales, en la resolución de las controversias. Pues ellos no son traducto- "la norma de juicio que suple omisiones de la ley, y que se funda en las prácticas seguidas en casos iguales 0 análogos". También, se habla de ella como: "la costumbre

que impera en los tribunales". sino que realizan una labor de interpretación de la Constitución, las leyes y reglamentos, impronta que posibilita que dichas concepciones afloren.

2 Las dos principales causales para la remoción de autoridades municipales son: el notable abandono de deberes y la falta de probidad que se localizan en la ley orgánica de municipalidades.

3 Vid, Rosales García, Carlos Manuel, "Análisis crítico del sistema de remoción de autoridades edilicias en el sistema electoral chileno", Revista de derecho electoral, número 8, Costa Rica, 2009.

4 UNAM. Instituto de Investigaciones Jurídicas. Diccionario Jurídico Mexicano, Tomo III, Editorial Porrúa, S.A. de C.V., México, 1998, p. 1980. 
Por lo que se considera a la jurisprudencia como "una pauta interpretativa que será aplicable a casos semejantes de igual forma, teniendo los justiciables... una fuente orientadora de la manera como se resolverá en el futuro cuestiones similares". ${ }^{5}$

De esta manera, podemos observar que la jurisprudencia es el medio para interpretar, integrar y delimitar las posiciones escritas de ese ordenamiento, es decir, fija con precisión el carácter vinculante, el sentido y alcance de estas $y$, al mismo tiempo, colma sus lagunas. ${ }^{6}$

La existencia de la jurisprudencia reviste gran importancia práctica, en tanto fomenta una deseable coherencia decisoria, brindando seguridad a los actores sociales y políticos; también sirve para actualizar y adaptar la legislación a nuevas realidades y demandas; y, finalmente, guía al estudio jurídico y al propio legislador, quien podrá ver en ella las falencias e insuficiencias de las reglas vigentes. ${ }^{7}$ Asimismo, la jurisprudencia también supedita a la adecuada selección de los criterios y principios que han de orientar la labor hermenéutica de los jueces:

"Al decantarse por intermedio de la jurisprudencia criterios vinculantes y relativamente estables sobre el modo en que las normas deben ser interpretadas por los operadores jurídicos, se promueve cierta coherencia resolutiva que, indudablemente, armonizada con el principio constitucional de igualdad, crea las condiciones de seguridad para los destinatarios de las normas".8

Se trata, entonces, de una herramienta puesta a disposición del operador jurídico para que reconozca en forma debida las disposiciones escritas del ordenamiento que debe aplicar a la realidad normada, al proporcionarle criterios calificados sobre su recto sentido y alcance, y sobre cómo colmar las lagunas de ese ordenamiento

5 Ojesto Martínez Porcayo, José Fernando, "Jurisprudencia electoral, aporte para el fortalecimiento de la jurisprudencia" en Revista de Derecho Electoral, Número 8, Costa Rica, 2009, p.11.

6 Ídem, p.13.

7 Ídem.

8 Sobrado González, Luis Antonio, "La jurisprudencia electoral como factor de profundización democrática en América Latina", op. cit., p.3. para, así, dar concreción al principio que proclama su plenitud hermética ${ }^{9}$.

Así, al fijarse las pautas de interpretación frente a la insuficiencia o a la oscuridad de la ley, aclarándola y supliendo sus deficiencias, nos proporciona un marco jurídico de referencia para la conducta de los diversos sujetos de la actividad política (partidos, candidatos, afiliados, etc. $)^{10}$. Por lo que al elaborarse una apropiada y correcta uniformidad de la jurisprudencia, se constituye una garantía de estabilidad jurídica ${ }^{11}$.

Asimismo, Fernando Ojesto Martínez expone dos aspectos que evidencian la relevancia de la jurisprudencia:

“a) La espontaneidad de la creación jurisprudencial: Si esta surge de la fuente viva que implica el análisis reiterado de las disposiciones vigentes, en función de su aplicación a casos concretos actuales, ella logra una actualización de la norma que la dinámica legislativa no puede alcanzar.

b) Su ejemplaridad: Al ser la jurisprudencia el conjunto de tesis derivadas de la solución reiterada de asuntos, constituyen un valioso material de orientación y enseñanza, que señala a los jueces, a las autoridades administrativas y a los ciudadanos, la solución de la multiplicidad de cuestiones jurídicas que contemplan, que suplen las lagunas y las deficiencias en el orden jurídico positivo y que pueden guiar al legislador en el sendero de la obra futura"12.

Por lo que podemos afirmar, que la interpretación de la norma y el papel creador del juzgador son los pilares en que descansa el perfeccionamiento del derecho. "No hay crítica interna sin interpretación y,

\section{Ídem, p. 2.}

10 González Roura, Felipe, "Justicia Electoral y resolución de conflictos: Quince años de experiencia Argentina" en Revista Jurídica Jalisciense, op.cit., p. 264.

11 Ídem, p. 265

12 Ojesto Martínez Porcayo, José Fernando, "Jurisprudencia electoral, aporte para el fortalecimiento de la jurisprudencia" en Revista de Derecho Electoral, op. cit., p. 22. 
paralelamente, la interpretación más importante es la que realiza el órgano resoluto de controversias"13.

En lo que respecta a la jurisprudencia como fuente del derecho electoral, esta "se constituye como un mecanismo fundamental para que el nuevo entramado jurídico en materia electoral, que permite a las autoridades responsables actuar bajo cualquier circunstancia con apego a la legalidad, y a los ciudadanos tener certeza del sentido y fundamento de la actuación de las autoridades" ${ }^{14}$.

La importancia de la jurisprudencia electoral en un sistema democrático depende, esencialmente, "del compromiso de los jueces electorales con la idea cardinal de profundización de las prácticas democráticas y de favorecimiento de una participación política de los ciudadanos cada vez más intensa y auténtica"15.

Para José Woldenberg, la interpretación en materia electoral no debe de dejar de ser el instrumento que colme los vacíos o la oscuridad legal, es pertinente en virtud de esa importancia, que la interpretación normativa debe ser ante todo una fuente de certeza:

"La interpretación que haga la autoridad electoral debe ser lo más ceñida a lo establecido a la norma, lo más mesurada y seria posible, de otra manera, en vez de ser una fuente de certeza, la actuación de la autoridad encargada de administrar justicia puede convertirse en el origen de dudas e incertidumbre"16.

Por lo que toda opinión fundada sobre el funcionamiento del Tribunal Electoral debe basarse en el estudio y análisis técnico, objetivo y profesional de las

13 Nieto, Santiago, Interpretación y argumentación jurídicas, op. cit., p. 277.

14 Becerra, Ricardo, Salazar Pedro y Woldenberg, José, La Reforma de 1996, op. cit., p. 171.

15 Sobrado González, Luis Antonio, "Tendencia de la justicia electoral latinoamericana y sus desafíos democráticos", op. cit., p. 173.

16 Woldenberg, José, "Orígenes, función y perspectivas del TEPJF", en Testimonios sobre el desempeño del TEPJF, op.cit., p.356. razones jurídicas expuestas por el órgano jurisdiccional para sustentar cada una de sus sentencias. ${ }^{17}$

De la misma manera, la jurisprudencia electoral ofrece antecedentes para la mejora de las leyes electorales y la adecuación de las mismas a criterios interpretativos constantes y consolidados. Además, tiene la tarea de colmar vacíos legales en materia electoral ${ }^{18}$.

Por lo que el valor de la
La interpretación de la norma y el papel creador del juzgador son los pilares en que descansa el perfeccionamiento del derecho.

\section{jurisprudencia electoral}

no solo beneficia a los actores políticos, sino también a la sociedad civil, al establecer criterios jurídicos de cómo será su actuación y de esta manera evitar indiscreciones por parte de los jueces electorales:

"La solvencia técnica y la independencia de criterio del juez electoral, así como resoluciones académicamente intachables no son suficientes para conjurar ciertos riesgos y evitar que el alegato jurídico se transforme en violencia callejera. Es necesario, además una jurisdicción electoral que, con gran presencia pública, ocupe ese vacío de autoridad y luzca ante la ciudadanía suficientemente protagónica confiable y robusta para preservar los cauces jurídicos en la resolución del conflicto político-electoral, lo cual solo se puede lograr mediante un adecuado posicionamiento institucional" ${ }^{\prime 19}$.

Sobre el tema de la obligatoriedad de la jurisprudencia electoral, el magistrado Leonel Castillo considera que debido a su naturaleza jurídica: "esta no tiene por objeto emitir disposiciones generales, abstractas e impersonales de carácter imperativo, sino

17 Orozco Henríquez, Jesús, Justicia electoral y garantismo jurídico, op. cit., p. 30.

18 González Roura, Felipe, "Justicia Electoral y resolución de conflictos: Quince años de experiencia Argentina" en Revista Jurídica Jalisciense, op. cit., p. 264.

19 Sobrado González, Luis Antonio, "La jurisprudencia electoral como factor de profundización democrática en América Latina", op. cit., p. 25. 
aplicar las leyes a los casos concretos, y cuando para esto resulte necesario interpretar o integrar los ordenamientos, lo debe hacer a través de una justificación argumentativa suficiente y persuasiva, con los métodos de interpretación existentes, para cumplir, inclusive aquí, con la obligación de fundar y motivar impuesta constitucionalmente a los juzgadores. En esta posición las tesis deben contener, por lo menos: 1. Los preceptos legales y/o principios jurídicos que son objeto de la interpretación. 2. El criterio asumido. 3. El método de interpretación empleado y 4. La expresión concisa de los argumentos expuestos para justificar el criterio adoptado" 20 .

Con esto, se crean buenos argumentos a favor de que haya un intérprete judicial para que las interpretaciones contengan armonía, coherencia y lógica, además de un sentido unificador.

En el caso de Chile, la jurisprudencia no constituye una fuente del derecho, conforme a lo dispuesto por el artículo tercero del Código Civil que establece que los efectos de los fallos solo afectan a las causas en que actualmente se pronunciaren. Sin embargo, cabe señalar, que las sentencias más relevantes "suelen ser publicadas en recopilaciones doctrinarias y sirven de elementos de juicio para acotar las interpretaciones constitucionales y legales y con frecuencia se ven citadas por los abogados y partes interesadas" 21 .

Por lo que podemos observar, la legislación electoral chilena no contiene un rubro para crear jurisprudencia, sino que solo se producen referencias no vinculantes y menos obligatorias. Por lo mismo, no se indica cuál es su valor e importancia de la jurisprudencia en el entramado judicial, pero sobre todo, no se genera una seguridad jurídica para los actores políticos y ciudadanos, pues no existe una obligación de aplicar o interpretar la norma de cierta manera.

20 Castillo González, Leonel, Reflexiones temáticas de derecho electoral, op. cit., p.293.

21 Valladares, Carmen Gloria, "sobre lo contencioso electoral y la jurisprudencia electoral en Chile", en El contencioso y la jurisprudencia electorales en derecho comparado, op. cit., p. 171.
Asimismo, tenemos que tanto el Tribunal Electoral Central y los regionales electorales valorarán las pruebas como jurado y de manera privada, esto no permite conocer el sentido de una interpretación permanente y tampoco permite generar un ambiente que garantice efectivamente los derechos políticos de los ciudadanos.

En primer lugar, examinaremos la jurisprudencia del TRICEL en dos grandes temas: las impugnaciones que se suscitaron por la cuestión del registro de candidaturas, el proceso electoral, la solicitud de nuevos escrutinios y por otro lado, la calificación de las elecciones; en segundo lugar, se analizarán las impugnaciones de los partidos políticos por las resoluciones del SERVEL y el Consejo Nacional de Televisión (CNTV).

Por lo que a continuación presentaré las apelaciones más relevantes presentadas cuando se impugnaban el registro de las candidaturas por supuestamente, no satisfacer los requisitos que contempla la normatividad electoral.

\section{IMPUGNACIONES POR LOS REQUISITOS ELECTORALES}

El supuesto incumplimiento de los requisitos para postular a un cargo de elección popular generó demasiados juicios para solicitar la cancelación del registro de varios candidatos, pues se reclamaba que el postulante no cumplía con todos los requisitos establecidos.

Los juicios para impugnar la inscripción de una candidatura se hacen en primera instancia ante Tribunales Electorales Regionales. El artículo 10 de la Ley $18.593^{22}$ dispone que corresponde a los TER calificar las elecciones, conocer de las reclamaciones, declarar inhabilidades y cumplir las funciones que les encomiende las leyes, agregando en el inciso final, que: "la resolución de las calificaciones y reclamaciones comprenderá también el conocimiento de cualquier vicio que afecte la constitución del cuerpo electoral o cualquier hecho, defecto o irregularidad que pu-

22 Ley modificada por la Ley 19.146. 
diera influir en el resultado general de la elección o designación, sea que haya ocurrido antes, durante o después del acto eleccionario de que se trate". Por consiguiente, si en el proceso de calificación de la elección se advierte la existencia de un vicio, el Tribunal Electoral Regional no puede desconocerlo $u$ omitir pronunciamiento a su respecto, siendo forzoso declarar lo que en Derecho corresponde, para concluir este proceso ${ }^{23}$.

Sin embargo, el TCE estimó que atendida la importancia que reviste asegurar a los electores que estén participando en un proceso transparente y democrático, el legislador estableció la preclusión de las acciones deducibles respecto de las distintas etapas sucesivas cumplidas del proceso eleccionario, de modo que, desde el momento en que una persona queda inscrita en el registro especial, esta tiene la calidad de candidato "para todos los efectos legales"24; disposición que, además, se encarga de precisar que la inscripción del candidato en el registro especial procede una vez ejecutoriada la resolución que acepta la candidatura.

Por ejemplo, si un candidato resulta electo y se comprueba por sentencia firme dictada en juicio criminal legalmente tramitado que la declaración de gozar de todos sus derechos electorales es falsa ${ }^{25}$, la nulidad de tal declaración y la de sus efectos legales posteriores, incluida su elección, debe ser solicitada ante el Tribunal Electoral Regional correspondiente, por consiguiente, para que se pueda reclamar este evento, es necesario tener siempre como antecedente previo la resolución penal que así lo declare.

Por lo que cobra importancia determinar el papel que juega la inscripción electoral frente a la existencia del derecho a sufragio. Tal como lo ha señalado el Tribunal Constitucional, "se debe considerar que la inscripción fue establecida con el único objeto de ejercer el derecho a sufragio pero no para acreditar que se posee dicho derecho, distinguien-

\footnotetext{
23 Sentencia rol 96-00.

24 Artículo 115 de la Ley número 18.695.

25 Artículo 107 de la Ley número 18.695.
}

do claramente entre la existencia de este y su ejercicio". ${ }^{26}$

De esta manera, el TCE estableció que se puede presentar esta clase de oposiciones en cualquier momento, desde el momento del registro hasta antes de la declaración de ganador al cargo de elección popular. Porque si no se cuenta con todos los requisitos, se cancela la candidatura, pero ya no podría alegarse después de que sea cosa juzgada, porque ya no sería dentro del proceso electoral propiamente.

Asimismo, el TRICEL estableció que en estos casos debía revisarse la situación legal del candidato y verificar que el tipo de sanción no fuera por algún delito que mereciera pena aflictiva ${ }^{27}$. Por lo que el Tribunal respaldó la inscripción de algunos candidatos al considerar reclamaciones, declarar inhabilidades y cumplir las funciones que les encomiende las leyes, agregando en el inciso inal, que: "la resolución de las calificaciones

y reclamaciones

el conocimiento de cualquier vicio que afecte la constitución del cuerpo electoral o cualquier hecho, defecto 0 irregularidad que pudiera influir en el resultado general de la elección o designación, antes, durante o después del acto eleccionario de que se trate".

26 Tribunal Constitucional. 8 de septiembre de 1986. R. t. 83, p. 93. Rol No. 38, considerandos 10 y 11. El derecho a sufragio se suspende según el número 2 del artículo 16 Constitucional, por hallarse la persona procesada por delito que merezca pena aflictiva o por delito que la Ley califique como conducta terrorista, siendo el Director del Servicio Electoral el responsable de velar por el cumplimiento de la suspensión, cancelando la respectiva inscripción. Artículo 53 letra f) en relación con el artículo 39 número 2 de la Ley número 18.556, sobre Sistema de Inscripciones Electorales y Servicio Electoral.

27 Artículo 73 de la Ley número 18.695. 
que sí cumplían con todos los requisitos para su postulación ${ }^{28}$.

Entre los requisitos para postular a un cargo político, se contempla que el no estar bajo pena de prisión o habiendo siendo absuelto en el tiempo de las elecciones, no era motivo suficiente para cancelar su inscripción, en opinión del TRICEL

Un punto fundamental, es saber en qué momento se puede impugnar una elección por la falta de requisitos, si después del momento de ser inscrito en el Servicio Electoral o cuando el candidato cometiera un delito con pena aflictiva dentro del proceso electoral.

Por ejemplo, en un caso (teniendo como referencia la línea temporal), el candidato perdedor impugnó la elección porque el candidato ganador tenía una clara inhabilitación para ocupar el cargo ${ }^{29}$. Por lo que el TCE señaló en este caso, que si el candidato triunfador en la fecha de declaración no se encontraba procesado penalmente, no lo afectaba la inhabilidad que se reclamaba.

Esto tiene que ver con la obligación de los postulantes a los cargos públicos de disfrutar con sus derechos políticos, al momento de la elección y antes de entrar en funciones públicas.

\section{DERECHOS POLÍTICOS VIGENTES}

\section{En Chile es un requisito fundamental, porque una persona que no cuenta con estos, no es reconocida como ciudadano en pleno goce de sus derechos políticos}

El goce de los derechos ciudadanos es un requisito básico para postular a un cargo de representación. En Chile es un requisito fundamental, porque una persona que no
28 Sentencia rol 94-00.

29 Sentencia rol 7-92. Además, de que el delito por el cual se procesaba al candidato le correspondía la pena consignada por el artículo 467 número 2 del Código Penal, en relación con el artículo 22 de la Ley de Cheques, por lo que su procesamiento no pudo inhabilitarlo, ya que su sanción no resultaba en una pena aflictiva. cuenta con estos, no es reconocida como ciudadano en pleno goce de sus derechos políticos (llegando incluso a la remoción de autoridades), por lo que no puede asumir ni continuar en el cargo ${ }^{30}$.

El artículo 13 de la Constitución chilena determina quienes son ciudadanos $y$, en su inciso segundo señala los derechos que otorga dicha calidad, entre los cuales está el derecho a sufragio.

La norma señala que son ciudadanos todos los chilenos que hayan cumplido dieciocho años de edad y que no hayan sido condenados por pena aflictiva. Para ser más específico, el artículo 37 del Código Penal dispone que para los efectos legales se consideran aflictivas todas las penas que sancionan crímenes, y entre las penas que sancionan simples delitos, las de presidio menor en su grado máximo.

Entre los requisitos para postular a un cargo político, se contempla que el no estar bajo pena de prisión o habiendo siendo absuelto en el tiempo de las elecciones, no era motivo suficiente para cancelar su inscripción, en opinión del TRICEL. ${ }^{31}$ Porque de acuerdo a lo dispuesto en el artículo 16 número 2 de la Constitución, la suspensión de la inscripción se produce cuando el afectado ha sido sometido a proceso por delito que merezca pena aflictiva y habiendo desaparecido la causal de suspensión con la emisión de la sentencia absolutoria a favor del reclamante. Por lo que el TCE confirmó varias candidaturas, bajo estas circunstancias.

En el caso de las apelaciones por el descubrimiento de una supuesta inhabilidad o incumplimiento de los requisitos para ser reconocido como ciudadano, también fue materia de análisis para el TCE. En estos casos, los candidatos no favorecidos con el voto apelaban ante el Tribunal para que se invalidara la elección y, además, se anularan esos votos, ya sea por ser un descubrimiento o una estrategia electoral, el reservarse exponer esa inhabilidad e intentar conseguir la anulación de la elección.

\footnotetext{
Sentencia rol 1-97.

31 Sentencia rol 37-97.
} 
En una situación particular, el TER de la II región consideró que los votos otorgados al candidato inhabilitado debían anularse, aunque se encontrara participando en la misma planilla con otros candidatos. Sin embargo, en el juicio de alzada, el TCE estimó que si bien era cierto que el candidato ya no contaba con sus derechos políticos vigentes, no menos cierto era que la lista la integraban diversos candidatos, por lo mismo revocó la sentencia del a quo y ordenó que solo tuviera efectos en el momento de designar a los Concejales ganadores, excluyendo al candidato descalificado ${ }^{32}$.

En otro caso, acaeció que la aspirante fue privada no tan solo del derecho a sufragar, sino también del de participar a cargos de elección popular, por la circunstancia de adelantarse unos cuantos días a inscribirse en los registros electorales, en una actitud diligente que no puede afectarle, sin que la autoridad destinada al efecto se lo observara en su debida oportunidad ${ }^{33}$.

El TCE estimó que en la situación planteada generaba una disyuntiva entre los derechos constitucionales, por un lado, y el acatamiento a una formalidad consistente en un plazo, por lo que el Tribunal, optó por salvaguardar los derechos ciudadanos de la apelante, restableciendo su derecho de sufragio, posibilitando su postulación al cargo de concejal.

En otra ocasión, se invalidó la victoria de un Alcalde, pues para tomar posesión y conservar su cargo público se necesita ser ciudadano en pleno goce de sus derechos. En este caso, el Alcalde electo fue sentenciado previamente al proceso electoral por "notable abandono de deberes", lo que confirmaba la remoción del Alcalde de la comuna de Pitrufquén, destitución declarada por el Tribunal Electoral de la IX Región de La Araucanía, por lo que se le inhabilitó para ejercer cualquier cargo público por el lapso de cinco años. Esta incapacidad legal no pudo tenerse en cuenta en su oportunidad, porque el fallo en cuestión quedó ejecutoriado con posterioridad a la fecha de la calificación del TER ${ }^{34}$.

Asimismo, el TCE estimó en esta elección que las preferencias de la ciudadanía a favor del candidato no podían ser consideradas como válidamente emitidas, en atención a que estas habían recaído en una persona imposibilitada para ejercer el cargo al que pretendió postular, y no podían, por ende, esas manifestaciones de la voluntad sobrepasar los efectos de una sentencia jurisdiccional ejecutoriada que lo sancionós ${ }^{35}$, con una inhabilitación que correspondía aplicar a todo Alcalde que es removido de su cargo.

De esta manera, el Tribunal decidió anular la declaración de candidatura, debiéndose anular En este caso, el Alcalde electo fue sentenciado previamente al proceso electoral por "notable abandono de deberes", lo que confirmaba la remoción del Alcalde de la comuna de Pitrufquén, destitución declarada por el Tribunal Electoral de la IX Región de La Araucanía, por lo que se le inhabilitó para ejercer cualquier cargo público por el lapso de cinco años. todos los votos obtenidos por el candidato; por lo que esos votos fueron declarados nulos, realizándose un nuevo escrutinio, eliminándose el nombre del candidato que se trataba de entre aquellos de la referida lista al practicarse de nuevo el escrutinio general.

Esto se realizó de esta manera, porque con las pruebas presentadas por el recurrente se acreditó la existencia del vicio de inhabilidad del candidato vencedor, lo que fue determinante para que el Tribunal acogiera la reclamación, por cuanto, de no hacerlo, estaría validando un vicio mayor, como lo sería la proclamación de un ciudadano al que la ley claramente le impedía desempeñar el cargo.

\footnotetext{
Sentencia rol 114-04.

35 Artículo 60 de la Ley de municipalidades.
} 
Otro de los requisitos básicos para postular a un cargo de representación popular es contar con la educación media. Esto ha sido motivo para impugnar el registro de candidaturas.

\section{EDUCACIÓN MÍNIMA}

El artículo 44 de la Constitución Política exige entre otros requisitos para ser elegido al cargo de representación haber cursado la enseñanza media o equivalente. Asimismo, el artículo 17 inciso segundo de la Ley 18.700 señala que el Director del Servicio Electoral deberá rechazar las declaraciones de candidatura que no cumEl concepto de plan con los requisitos estaresidencia no blecidos ${ }^{36}$.

está definido en

la legislación, pero la definición de domicilio sí lo está.

Sin embargo, en varios casos el TCE modificó la resolución del Servicio Electoral, pues algunos candidatos sí satisfacían el requisito de la escolaridad media ${ }^{37}$. Por ejemplo, en el caso 15-89, el apelante fundó su reclamo en que a la fecha de solicitar su inscripción acompañó un certificado emanado de la Secretaría de Estudios de la Facultad de Derecho de la Universidad de Chile, que acreditaba que durante los años 1941, 1944 y 1946 fue alumno regular de la carrera de Derecho.

En este caso, el TCE consideró que esta constancia comprobaba suficientemente el requisito que prescribe la Constitución, para ser elegido al cargo de Diputado, demostrándose que el postulante había cursado la enseñanza media. Por tanto, el apelante cumplía sobradamente la exigencia de haber cursado la enseñanza media, por lo que el TCE dejó sin efecto la resolución del Director del Servicio Electoral que rechazaba el registro de su candidatura, y ordenó al SERVEL inscribir esa candidatura.

36 Sentencia rol 48-89.

37 Sentencia rol 16-89, 21-89, 22-89, 23-89, 24-89 y 32-89.
Otro requisito fundamental para postular a un cargo de representación es el de la residencia del candidato en el distrito, comuna o región ${ }^{38}$.

\section{RESIDENCIA}

El TCE al interpretar qué se debía entender por residencia, señaló que conforme al Diccionario de la Real Academia Española (RAE), el vocablo "residencia" significa "acción o efecto de residir, lugar en que se reside" y "residir" es "estar establecido en un lugar", de lo que se infiere que se trata de un término amplio y que queda entregado al ánimo de las personas el determinar dónde y en qué lugar se asientan, en qué punto geográfico desean establecerse dentro del territorio nacional; ya sea en forma temporal o permanente. Y como el concepto de residencia no está definido en la legislación, pero la definición de domicilio sí lo está, el TCE concluyó que la ley permite que se pueda tener más de un domicilio; igualmente, las personas y el particular, por lo que los ciudadanos pueden tener más de una residencia ${ }^{39}$.

Por lo que el TCE estableció que el término residencia sería entendido como: "... el lugar determinado donde una persona establece el centro de sus intereses jurídicos y en el cual se encuentra habitual o permanentemente" y por morada, "la relación de hecho de una persona con un lugar, casa o recinto, donde esa persona vive o permanece. Semejante permanencia puede ser ocasional, accidental o momentánea, a diferencia de lo que sucede con la residencia, que tiene mucho mayor grado de estabilidad". ${ }^{40}$

38 Por ejemplo, el artículo 60 inciso c) de la ley 19.130 señala que los alcaldes y concejales deben tener residencia en la región a que pertenezca la respectiva comuna o agrupación de comunas.

39 En este caso se trataba de un embajador con domicilio en Arabia Saudita, Sentencia rol 16-93.

40 Sentencia rol 20-01. Corte Suprema de Justicia, 17 de junio de 1986. F. del M. Número 331, Sentencia $8^{a}$, página 392 (C. $2^{\circ}$ a $7^{\circ}$, pp. 393-394). En idéntico sentido se ha pronunciado la Comisión de Constitución, Legislación y Justicia del Senado en un informe respecto a la expresión residencia, señalando que: la misma "es permanencia física y no meramente jurídica: presencia real y no ficticia o teórica, salvo en lo concerniente a quienes precisamente 
Sin embargo, hubo un caso en que no se pudo comprobar la residencia de un candidato en la región ${ }^{41}$. Pues el artículo $3^{\circ}$ bis inciso $3^{\circ}$ de la Ley número 18.700, expresa que las declaraciones de candidaturas que presente un pacto electoral solo podrán incluir candidatos de los partidos que se encuentren legalmente constituidos en la respectiva región. Por lo que el TRICEL concluyó que el reclamante no podía postular al cargo por la circunscripción electoral que pretendía.

La falta de residencia en la comuna también fue una fuente de impugnaciones de candidaturas a los cargos públicos del municipio, por lo que el Tribunal declaraba si el candidato inscrito contaba con esa residencia, marcando la diferencia entre residencia, vecindad o domicilio $y$, poder aclarar si el candidato contaba con este requisito y por tanto, confirmar o rechazar su candidatura ${ }^{42}$.

En estos casos, el Tribunal si bien formuló la distinción entre domicilio y vecindad, consideró los requisitos mínimos el acreditar la residencia, pero no criticó la acepción y comprobación de la residencia. Ahora, si bien este requisito fue motivo para solicitar la anulación del triunfo del candidato elegido, en ningún caso, el Tribunal Electoral invalidó o anuló alguna elección municipal por la falta de residencia ${ }^{43}$.

Otro requisito para competir por un cargo político, es la entrega de una declaración jurada de no estar inhabilitado para postular a un cargo de representación, esto significa que el candidato manifiesta ante un notario que cuenta y goza con sus derechos ciudadanos. Sobre este rubro el TCE advirtió que si el postulante no se encontraba en pleno goce de su ciudadanía, no podía postular a ninguna candidatura ${ }^{44}$.

están ausentes por representar ante el Parlamento a las respectivas Circunscripciones".

41 Sentencia rol 95-89.

42 Sentencia rol 81-04.

43 Sentencia rol 5-92.

44 Sentencia rol 61-00.

\section{DECLARACIÓN JURADA}

La declaración jurada es un documento notariado que debe contener la aseveración del aspirante a un cargo de representación popular, de que goza plenamente de sus derechos políticos ${ }^{45}$.

Esta declaración notarial debe presentarse al momento de la inscripción ante el Servicio Electoral. En varios casos, el Director del SERVEL estimó que esta declaración no contaba con los requisitos que contempla la ley, por lo que el TCE tuvo que conocer y resolver sobre el cumplimiento de este requisito, para confirmar o anular esa candidatura ${ }^{46}$.

$$
\begin{array}{r}
\text { El Tribunal, } \\
\text { apreciando como } \\
\text { jurado, estimó en } \\
\text { varios casos, que el } \\
\text { mandato apelado } \\
\text { sí cumplía con lo } \\
\text { estipulado en la ley. }
\end{array}
$$

Pero, al ser tan solo una declaración, quedará en suspenso saber si esta es fidedigna, si mintió u omitió alguna inhabilidad para postular a cualquier cargo. Por lo que en varias apelaciones, el TCE calificó la inscripción y examinó los documentos allegados por la parte inconforme, resolviendo si le afectaba algún vicio o incapacidad legal para ser candidato ${ }^{47}$.

Por ejemplo, en el caso rol 24-97 se apeló la resolución del SERVEL, porque al parecer del director del órgano administrativo electoral central, la declaración entregada para postular a un cargo público no señalaba la fecha de otorgamiento ${ }^{48}$. Sin embargo, el TCE estimó que la declaración notarial en comento, si cumplía con los requisitos exigidos para ser candidata a un cargo en el parlamento, por lo que ordenó al SERVEL su inscripción ${ }^{49}$. En otros casos, los candidatos simplemente no entregaron esta de-

Sentencia rol 46-96. Artículo 98 de la ley 18.695 y el artículo $4^{\circ}$ inciso final de la ley número 18.700 .

46 Sentencia rol 50-89.

47 Sentencia rol 47-00.

48 Lo que es un requisito, que estipula el artículo 425 código orgánico de tribunales.

49 Sentencia rol 24-97. 
claración. En esta clase de casos, el TCE confirmó la cancelación de sus inscripciones ${ }^{50}$.

\section{MANDATO DE REPRESENTACIÓN}

Dentro de los requisitos para aspirar al cargo de Alcalde o Concejal se debe entregar un mandato de representación ${ }^{51}$. Este mandato debe ser elaborado por el notario designado por la ley, ${ }^{52}$ por lo que si no se entrega este requisito (con todas sus formalidades) se debe cancelar la inscripción, aunque se tratase de subsanar en la apelación ante el TCE ${ }^{53}$. En otros casos, el Tribunal, apreciando como jurado, estimó en varios casos, que el mandato apelado sí cumplía con lo estipulado en la ley ${ }^{54}$.

\section{INSCRIPCIÓN EN UN PARTIDO POLÍTICO PARA SU POSTULACIÓN}

El TRICEL ha declarado y reiterado. que solo podrán ser candidatos por los partidos políticos los ciudadanos ${ }^{55}$ que figuren en el duplicado del respectivo registro general de afiliados que posee el SERVEL ${ }^{56}$.

El candidato se encuentre registrado en el Partido Político que lo postula y que conste su filiación ante el Servicio Electoral En lo que respecta a la postulación por un partido político distinto al primer partido que lo postuló, deberá prevalecer la primera inscripción. En este caso, el reclamante pretendía una nueva inscripción de candidatura con posterioridad a la primeramente efectuada y aceptada de conformidad a la ley, ello hubiera implicado una vulneración flagrante a la disposición contenida en el artículo $3^{\circ}$, inciso $3^{\circ}$ de la Ley número 18.700 , por lo que no podrían subsistir simultáneamente dos inscripciones

\footnotetext{
50 Sentencia rol 25-97, 18-01, 21-01, 22-01 y 23-01.

51 Artículos 114 y 115 de la ley número 18.695.

52 Sentencia rol 75-00. Asimismo, el TCE remite los antecedentes al juez del crimen en caso de falsedades o alguna supuesta falsificación.

53 Sentencia rol 51-96.

54 Sentencia rol 22-00.

55 Artículo $9^{\circ}$ de la Ley número 18.700.

56 Sentencia rol 60-89.
}

idénticas para un mismo acto electoral, fueren estas patrocinadas por un partido o pacto político o bien que tuvieren el carácter de independiente ${ }^{57}$.

El TCE estimó que los candidatos en esta condición deben acogerse y aceptar la primera de las candidaturas inscritas de que se trate, por lo que corresponde al Director del Servicio Electoral el pronunciarse sobre la aceptación o rechazo de cada una de las declaraciones de candidaturas que se le presenten, todo ello de conformidad a lo preceptuado en artículo 17 de la Ley sobre Votaciones Populares y Escrutinios.

Un tema básico, es que el candidato se encuentre registrado en el Partido Político que lo postula y que conste su filiación ante el Servicio Electoral ${ }^{58}$. Uno de los problemas que resolvió el TCE era la forma en cómo se habían llevado esas inscripciones, pues si estaban registrados previamente en un partido político, aun sin su consentimiento, no podían ser candidatos independientes ${ }^{59}$ o si no habían realizado la baja de sus patrones de afiliados. También se cancelaba la inscripción, por estar postulado por un partido diferente al que lo patrocinaba ${ }^{60}$.

Por lo que se estableció implícitamente como obligación del candidato, el averiguar su relación con el partido que lo postulaba, así como su debida y efectiva baja de los patrones de los partidos políticos previos a esa candidatura ante el SERVEL, y que por lo menos se hiciera un par de meses antes de su inscripción ${ }^{61}$.

Un requisito adicional para los candidatos independientes es demostrar fehacientemente e indubitablemente, su desvinculación de cualquier partido político antes de su inscripción como independiente, pues como señala la ley: "Los candidatos independientes, en todo caso, no podrán haber estado afiliados a un partido político dentro de los dos me-

\footnotetext{
Sentencia rol 90-89.

Artículo $4^{\circ}$ inciso $4^{\circ}$ de la ley número 18.700 .

Sentencia rol 52-96.

Sentencia rol 25-96.

Sentencia rol 77-96.
} 
ses anteriores al vencimiento del plazo para presentar las declaraciones de candidaturas", por lo que es obligación del candidato verificar esta, para desafiliarse del partido político ${ }^{62}$.

Sin embargo, acaeció que en una postulación independiente un exafiliado del Partido Demócrata Cristiano (expulsado por la unanimidad de los miembros de su Tribunal Supremo en 1992) se registró como candidato ciudadano, pero el partido político no realizó el trámite administrativo de su baja ante el SERVEL, por lo que seguía inscrito en las listas del partido en cuestión ${ }^{63}$. Por lo que el TCE, al valorar libremente las pruebas sentenció que era dable concluir que desde noviembre de 1992 el reclamante recuperó la calidad de ciudadano independiente y que por razones no imputables a su voluntad, la expulsión no fue debidamente comunicada al Servicio Electoral, ${ }^{64}$ por lo que ordenó al SERVEL la inscripción del recurrente.

Ahora debe tenerse en consideración, que la norma señala que "todo afiliado a un partido político podrá renunciar a él, en cualquier momento y sin expresión de causa", ${ }^{65}$ con lo que el legislador quiso expresamente reafirmar los principios esenciales de libertad y de democracia interna que deben existir en los partidos políticos, ya sean legalmente constituidos o en proceso de formación. Porque de aceptarse una tesis contraria, traería consigo una flagrante contravención al derecho fundamental establecido en el artículo 19 número 15 de la Constitución, norma que protege a los ciudadanos del monopolio de la participación ciudadana en actividades políticas, por lo que se debe garantizar el más amplio pluralismo ideológico, al prevenir que nadie puede ser obligado a pertenecer a ninguna asociación ${ }^{66}$.

\footnotetext{
62 Sentencia rol 32-96.

63 Sentencia rol 48-96.

64 Artículo 20 de la Ley número 18.603.

65 Inciso $2^{\circ}$ del artículo 19 de la Ley Orgánica Constitucional número 18.603 de los Partidos Políticos.

66 Sentencia rol 12-93.
}

Pero si los partidos políticos no hicieran la debida cancelación del registro del exafiliado, el TCE ha estimado que para establecer esa desafiliación (sin que se hicieran valederas las alegaciones de error administrativo en cuanto a no comunicar una desafiliación que se habría cursado internamente), ${ }^{67}$ el candidato tiene la responsabilidad de investigar si fue debidamente desincorporado del partido político, para postular o patrocinar alguna candidatura independiente. Por lo que en varios casos, La ley de votaciones señala que para esta clase de postulación

se necesita el patrocinio mínimo del cinco por ciento de los ciudadanos

inscritos en ese distrito, comuna 0 región. el TCE señaló que si la afiliación se encontraba todavía en registros del Servicio Electoral, no podía participar como candidato independiente ${ }^{68}$.

\section{PATROCINIO PARA CANDIDATOS INDEPEN- DIENTES}

En el sistema electoral chileno, los requisitos para las candidaturas independientes aumentan. Uno de esos requisitos es contar de manera efectiva con un mínimo de patrocinadores. La ley de votaciones señala que para esta clase de postulación se necesita el patrocinio mínimo del cinco por ciento de los ciudadanos inscritos en ese distrito, comuna o región ${ }^{69}$.

Este requisito adicional es examinado en primer lugar por el SERVEL que decide sobre su inscripción y en caso de ser negativa su resolución, se apelaba esa resolución ante el Tribunal Electoral ${ }^{70}$. Por lo que en el tema de las inscripciones independientes, tenemos que las apelaciones que presentaron los candidatos sin respaldo de un partido político, provocó la actuación y definición final del TCE.

\footnotetext{
67 Sentencia rol 13-89.

68 Sentencia rol 12-89, 18-89, 35-89, 43-89 y 44-89.

69 Artículo 10 párrafo II de la Ley de Votaciones.

$70 \quad$ Artículo 11 de la Ley No.18.700 sobre Votaciones Populares y Escrutinios.
} 
Un punto importante, que debo advertir es que los patrocinadores de una candidatura independiente no deben estar inscritos en un partido político, pues en caso contrario se llegaba a la cancelación de varias candidaturas independientes, al comprobarse la afiliación política de los patrocinadores ${ }^{71}$.

En el caso sobre impugnación de candidaturas independientes a la Presidencia de la República, solo ha existido una reclamación electoral desde 1989. Esta apelación se rechazó porque en el informe rendido por el Director del Servicio Electoral, señalaba que Gonzalo Townsend Pinochet no cumplió con los requisitos exigidos por la ley en lo relativo a la cantidad mínima de patrocinantes válidos, lo que permitió resolver al Tribunal Calificador de Elecciones, que la pretensión del ocurrente era inválida ${ }^{72}$.

Por lo tanto, se necesita el requisito material para que sea válido el registro del candidato independiente contar con un número mínimo de patrocinadores para postular al cargo de representación, pues el no acreditar debidamente con todos los requisitos legales, cancela el registro como aspirante a los cargos públicos. Pero en este requisito para los independientes, se puede negar la inscripción al candidato si más del $5 \%$ de sus patrocinadores se encuentran inscritos en un partido político, lo que invalidaría esa candidatura.

En un asunto en particular, el reclamante se inconformó por la sentencia del Servicio Electoral porque al parecer del apelante, la Constitución en su artículo 18 consagra la plena igualdad entre los independientes y los miembros de los partidos políticos y, por otra parte, transgrede el artículo 19 Constitucional, número 5 inciso $3^{\circ}$, señala que nadie puede ser obligado a pertenecer a una asociación ${ }^{73}$.

Este apelante señaló que el patrocinio político por los ciudadanos al candidato independiente debe basarse en la buena fe, pues este principio inspira a cumplir la Constitución y a confiar en las perso- nas. Por lo que la ley no puede exigir algo que tanto normativa como prácticamente no es posible de realizar. Además, el sentido verdadero de leyes es que sea el pueblo el que elija o sus autoridades y no sean excluidos a priori por requisitos de forma, y que inclusive sean imposibles de comprobar, que ni siquiera el mismo Servicio Electoral dispone de las renuncias ante el SERVEL de la región, menos aún pudiese tener una renuncia que eventualmente hubieran cancelado su inscripción ante el presidente del partido correspondiente. Y, por otra parte, se han objetado los patrocinios de varios ciudadanos por aparecer inscritos en otro distrito y otros por no estar inscritos, los cuales se han trasladado e inscrito oportunamente ${ }^{74}$.

Sobre este tema, el criterio que ha asentado el TCE respecto de la causal consignada en la ley de votaciones exige para las candidaturas independientes el patrocinio de un número de ciudadanos igual o superior al cinco por ciento de los que hubieren sufragado en el Distrito o Circunscripción Senatorial según correspondiere. Pero si hay más del $5 \%$ de patrocinadores con condiciones de inhabilidad para favorecer al candidato independiente, se deberá negar su inscripción.

El TCE consideró en el inciso final del artículo 17 de la ley de votaciones, que las declaraciones de candidaturas independientes patrocinadas por personas afiliadas a algún partido político no invalidarán la candidatura de que se trate, salvo que estas afiliaciones representen más del $5 \%$ del total de patrocinantes ${ }^{75}$.

Con esto, la única finalidad resultante sería colocar un obstáculo casi insalvable a la inscripción de candidaturas independientes, pues introduce una variable respecto a la cual el interesado en inscribir una candidatura no tiene ningún control de cuál es la exacta calidad de los patrocinantes, desde el punto de vista de su independencia o afiliación a partidos políticos.

\begin{tabular}{ll}
\hline 71 & Sentencia rol $19-96$ \\
72 & Sentencia rol $59-93$ \\
73 & Sentencia rol $11-89$
\end{tabular}

\footnotetext{
$74 \quad$ Sentencia rol 30-01.

75 Sentencia rol 31-01.
} 
Es un hecho que la verificación de la efectividad de esta circunstancia resulta muy difícil, porque la consulta de afiliación política o cancelación de inscripción es un trámite que debe realizar personalmente el interesado ante el Servicio Electoral y esta información se encuentra disponible en forma pública, por expreso mandato constitucional ${ }^{76}$.

En consecuencia, y dado el principio de buena fe que se traduce en la obligación respecto a los patrocinantes de declarar bajo juramento que no están afiliados a ningún partido político legalmente constituido o en formación, no tendría por qué el interesado en inscribir una candidatura independiente suponer la mala fe de las personas que voluntariamente han concurrido a la Notaría para patrocinar su candidatura.

A todo lo anterior, debemos agregar que el sistema electoral vigente en Chile abre la posibilidad de que los ciudadanos sean incorporados en los Registros de los Partidos Políticos sin contar con su consentimiento, por cuanto los Partidos envían para estos efectos nóminas al Servicio Electoral que contienen la individualización de los "militantes incorporados" pero en muchos casos no están suscritas por ellos. Por lo que resulta evidente que lo que persigue la legislación electoral es garantizar que los candidatos independientes tengan efectivamente la calidad de tales, para lo cual exige que los ciudadanos que patrocinen a dicho candidato, tengan la misma calidad de independientes.

Por lo que debemos concluir que la intención de todas las normas que regulan esta materia no es sino que un candidato independiente sea aceptado como tal cuando cumple dos premisas: 1) no estar afiliado a ningún partido político y 2) que a lo menos un $95 \%$ del número mínimo de patrocinantes que se requieren para postular, tampoco se encuentren afiliados a un partido político.

La interpretación señalada por el TRICEL cae en la incongruencia de sancionar al candidato que pu-

76 Artículo 19, fracción 15 , inciso $5^{\circ}$ de la Constitución Política chilena. diera tener más patrocinantes de los requeridos por la legislación, al exigirle, como un requisito adicional no contemplado en la legislación, siempre que sobrepase el mínimo de patrocinantes que se exige por ley; igualmente, esté obligado el candidato a mantener la proporción 95\% independiente, 5\% máximo de militantes ${ }^{77}$.

Asimismo, el TCE ha establecido que el postulante independiente es el responsable de hacer las averiguaciones pertinentes ante el Servicio Electoral para evitar ulteriormente encontrarse en la situación presentada $y$, por tanto, se rechace su candidatura $^{78}$. Pero también ha señalado el Tribunal Electoral Central, que los ciudadanos que participaron con su firma al proceso de formación de alguna colectividad política, mal podrían tener a esa fecha la calidad de militantes afiliados a un partido político que se esperaba que existiera, pero que en definitiva no logró nacer a la vida jurídica, por lo que consecuentemente deben ser considerados como ciudadanos independientes y con posibilidad de patrocinar candidaturas ciudadanas ${ }^{79}$.

\section{FORMALIDADES DEL ESCRITO DE DEMANDA}

El TRICEL ha sido bastante estricto en las cuestiones de forma y de los tiempos procesales, porque de acuerdo con lo dispuesto en el número 1 del Auto Acordado sobre recurso de apelación contra la sentencia de los Tribunales Electorales Regionales con motivo de las declaraciones de candidaturas a concejales, ${ }^{80}$ el escrito de apelación debe contener las peticiones concretas que se someten a la consideración del TCE. Por lo que declaró en bastantes ocasiones la inadmisibilidad del recurso, sin más

\footnotetext{
Sentencia rol 73-05.

78 Sentencia rol 75-05.

79 Sentencia rol 85-89.

80 Diario Oficial de 28 de junio de 2000.
} 
trámite, porque el escrito respectivo no contenía peticiones concretas ${ }^{81}$.
Lo que ha generado

que en algunas

ocasiones puedan

cometerse errores en

la forma en como se

llevaron los procesos

desde la instalación de

la mesa receptora, el

conteo, las personas

designadas suplentes
En otro asunto, el TCE declaró su incompetencia por presentarse directamente ante él un recurso, por la inhabilidad de un candidato que postulaba a Concejal; pero que, además, tenía un proceso penal pendiente ${ }^{82}$. Por lo que el Tribunal sentenció que no era competente para pronunciarse sobre

la apelación presentada, porque eso era labor del TER como tribunal de origen.

En general, el TRICEL empieza el análisis de las demandas, examinando que se cumplan las cuestiones de forma y posteriormente las de fondo. Entre los requisitos de forma para presentarse a deducir un interés legítimo en un juicio electoral, es que los actores cuenten con personería para presentar acciones y excepciones, por lo que si no se tiene tal carácter no está acreditada tal ${ }^{83}$.

En otros casos, el apelante no compareció dentro del plazo fatal del tercer día que establece el Número $4^{\circ}$ del Auto Acordado del Tribunal Calificador de Elecciones, sobre Tramitación y Fallo de los Recursos de Apelación ${ }^{84}$ y por tanto, el plazo para hacerlo se encontraba vencido. Por lo que el TCE declaró desiertos los recursos no ejercidos o abandonados por inactividad procesal ${ }^{85}$.

Con esto concluimos el análisis de las sentencias que resolvió el TCE cuando se impugnaban el registro de las candidaturas, por no satisfacer los requisitos contenidos en la normatividad electoral.

82 Sentencia rol 25-04.

83 Sentencia rol 20-96.

84 Diario Oficial del 18 de abril de 1988.

85 Sentencia rol 23-96.
Por lo que ahora entraremos a la revisión de las sentencias que elaboró el Tribunal por impugnaciones por la manera en como se llevaron las elecciones, i.e. los recuentos, la conducta de los actores políticos, el llenado de las actas, etc. Pero aquí hay un detalle importante, en varias ocasiones durante la etapa de los registros de inscripción no se presentaban los recursos o no se exhibía la inhabilidad que señalaba la falta de requisitos del candidato, sino que ejercían este derecho durante el proceso electoral o en el momento de los resultados definitivos.

Los ocurrentes presentaban ante el TCE un recurso para señalar la invalidez o la incapacidad del candidato ganador para ejercer ese cargo de representación, por no contar con los requisitos, ya sea por situaciones supervinientes o como estrategia jurídico-política.

\section{IMPUGNACIONES POR EL DESARROLLO Y RE- SULTADO DE LAS ELECCIONES}

En esta sección, analizaremos los reclamos emanados sobre el conteo, desarrollo y manejo de los votos, así como las impugnaciones de los resultados de las elecciones a los cargos de representación democrática.

En Chile, los procesos electorales son llevados por los ciudadanos, esto por supuesto tiene la ventaja de que no haya intervención del aparato del Estado para poder manipular los comicios, pero también tiene en contra ciertas cuestiones, como los errores humanos. Lo que ha generado que en algunas ocasiones puedan cometerse errores en la forma en como se llevaron los procesos desde la instalación de la mesa receptora, el conteo, las personas designadas suplentes, etc., cuestiones que tienen que ver directamente con la administración de la casilla electoral; lo que en resultados estrechos pueden hacer variar la balanza y, por tanto, modificar el resultado final.

Estas impugnaciones son resueltas por el Tribunal Electoral, que determinará si sus pretensiones son reconocidas o simplemente considere que si bien pueden existir anomalías no substanciales, no tienen por qué anularse la votación de esa mesa receptora, lo que invalidaría el resto de los sufragios de esa comunidad, distrito o región. 
Por otro lado, observaremos la conducta que ha tenido el TCE al resolver las solicitudes de los justiciables. Aquí, examinaremos si el Tribunal ha seguido el debido proceso, ${ }^{86}$ como el derecho de audiencia, reciprocidad, definitividad, el derecho de defensa, entre otros derechos adjetivos.

\section{SE NIEGA RECUENTO}

Para el TCE es fundamental que se señale expresamente en el recurso de apelación que se pretende, que se adminiculen las pruebas con los supuestos agravios y que respalden sus pretensiones, i.e., en el caso del recuento de los votos debe señalarse exactamente las mesas impugnadas, las causas del porqué del nuevo escrutinio, etc.

A partir del reestablecimiento de la democracia en Chile, solo se ha presentado una impugnación en las elecciones al Poder Ejecutivo. Esto sucedió en los comicios presidenciales de 1999, cuando los encargados de la candidatura de Joaquín Lavín Infante solicitaron que se rectificaran los escrutinios, en atención a que se habrían cometido omisiones y errores en diversas mesas receptoras de sufragios ${ }^{87}$.

Los representantes jurídicos de Lavín fundaron y argumentaron su petición en que los resultados generales de la votación señalaban que los candidatos Lagos y Lavín obtuvieron 3.377 .142 y 3.341 .296 votos, respectivamente, con una diferencia que no superaba el $0.49 \%$ del total de sufragios, en tanto que los votos nulos y blancos fueron 215.944, lo que representaba una cifra seis veces superior a la diferencia que separaba a los candidatos, circunstancia que adquiría una gran importancia, por la gran cantidad de votos objetados o marcados y el hecho que, "reiterada y masivamente", cuando esos votos que favorecían a Lavín no fueron bien escrutados en

86 La Corte Interamericana de Derechos Humanos ha considerado que el debido proceso abarca "las condiciones que deben cumplirse para asegurar la adecuada defensa de aquellos cuyos derechos u obligaciones están bajo consideración judicial" (Opinión consultiva OC-9/87).

87 Sentencia rol 25-99. las mesas de recepción de votos ${ }^{88}$. Por lo que solicitaron que se revisaran las mesas que indicaban en su demanda y todas aquellas que se encontrasen en idéntica situación, esto es, aquellas en que las actas revelaran diferencias entre el número de electores que sufragaron y el total de votos escrutados. Pero sobre todo, indicaron que la rectificación invocada podría producir una modificación en las mayorías relativas o en la diferencia de votos entre los candidatos aludidos, situación que podría ser esencial, en una segunda votación, para determinar el candidato elegido.

En su deliberación sobre este recurso de reclamación electoral, el TRICEL estimó que con base en el artículo $3^{\circ}$ del Auto Acordado, que disponía que las reclamaciones deben ser fundadas, señalándose el número de sufragios reclamados $y$, además, determinaron que se deben acompañar todos los antecedentes en que se basen sus objeciones ${ }^{89}$.

Por lo que el TCE al resolver la solicitud de rectificación señaló que los representantes de Joaquín Lavín no indicaron ni siquiera aproximadamente el número de votos que reclamaban para su candidato y que no se habrían escrutado correctamente en las mesas receptoras; $y$, que si bien indicaban, a vía ejemplar, alguna de estas mesas como aquellas cuyos cómputos resultarían afectados por la omisión denunciada, lo cierto era que su pretensión se extendía a todas las mesas en que pudiera detectarse la misma irregularidad, lo que importaba la totalidad del universo de las mismas; por lo que concluyeron que la solicitud no se ajustaba a lo prevenido en la Ley de Votaciones y en el Auto Acordado que reglamentaba el mecanismo de impugnación en el resultado de los escrutinios realizados en las mesas receptoras de votos, por lo que con base en los antecedentes

88 Las mesas impugnadas fueron Cerro Navia mujeres; Chillán mujeres; Conchalí El Cortijo varones; Estación Central, Huechuraba mujeres; Independencia mujeres; La Cisterna varones; La Florida, La Granja varones; Linares mujeres; Lo Espejo, Macul, Pedro Aguirre Cerda, Pudahuel sur mujeres, Quilicura mujeres; Quinta normal varones, Recoleta mujeres; Renca, San Bernardo, San Ignacio varones; San Miguel, san Ramón mujeres; Santiago y en la comuna de Victoria, en la mesa de varones.

$89 \quad$ Elaborado el 7 de diciembre de 1999. 
que ellos entregaron, resultaron insuficientes para sustentar su reclamación.

Adicionalmente, los representantes jurídicos de Lavín tampoco cumplieron con el requisito sustantivo de fundarse en hechos que hubieren dado lugar a la elección de un candidato u opción distinta de la que habría resultado de no mediar el vicio u omisión denunciado, es decir, lo que se exigía, era que estos

Por lo que el Tribunal atendiendo el mérito de los antecedentes contenidos en esas impugnaciones y, en especial, dando cumplimiento a lo dispuesto por el artículo 103 de la Ley sobre Votaciones Populares y Escrutinios, decidió no practicar el escrutinio de las mesas receptoras de sufragios que habían sido materia de esos reclamos, porque los apelantes no señalaron claramente los requisitos estipulados. últimos constituyeran la causa de una alteración en los resultados de la elección en que se produjeron y no en los de ulteriores actos eleccionarios. Por estos motivos, principalmente, el TRICEL rechazó este recurso de reclamación electoral.

Asimismo, en las sentencias sobre impugnaciones sobre los resultados en las elecciones de Diputados y Senadores de la República, se observó en varias ocasiones que las apelaciones no presentaban los requisitos exigidos por la ley y menos los solicitados por el TCE. Sin embargo, en un afán de constatar ciertos resultados ofrecidos, el Tribunal llegó en varios casos a revisar una tercera parte de las mesas impugnadas, pero sin modificarse sustancialmente el resultado previo ${ }^{90}$.

En la mayoría de estos asuntos, se solicitaba que se realizara un nuevo escrutinio de todas las mesas receptoras de sufragios $y$, en subsidio, pedían la rectificación de los mismos en relación a los votos declarados nulos por mesa y los Colegios Escrutadores. En estas impugnaciones, la mayoría de las veces acompañaron sus recursos con una gran cantidad

\footnotetext{
$90 \quad$ Sentencia rol 1-90
}

de actas de escrutinio correspondientes de las diversas mesas receptoras de sufragios de la Comuna, Distrito o Circunscripción.

Ante estas solicitudes, el TCE advirtió que varios de esos reclamos contenían claros defectos en la forma de su presentación, desde que las peticiones concretas insertas en él y lo que sometían a la decisión del Tribunal no era coincidente con los fundamentos esgrimidos en el mismo (principio de congruencia).

En efecto, apareció que no se citaba alguna causal legal de nulidad del acto eleccionario o de rectificación de escrutinios, -lo que aún ni siquiera se solicitaba- por lo que carecía de causa la parte ocurrente del mismo, en cuanto planteaba y solicitaba la revisión total y completa de la votación y del escrutinio general de la elección. Esas inconsistencias eran suficientes para que el TCE declarara su inadmisibilidad ${ }^{91}$.

En diversas ocasiones, los ocurrentes solicitaban la realización de un nuevo escrutinio. Por lo que el Tribunal atendiendo el mérito de los antecedentes contenidos en esas impugnaciones $y$, en especial, dando cumplimiento a lo dispuesto por el artículo 103 de la Ley sobre Votaciones Populares y Escrutinios, decidió no practicar el escrutinio de las mesas receptoras de sufragios que habían sido materia de esos reclamos, porque los apelantes no señalaron claramente los requisitos estipulados. Por lo que el TCE sentenció que era innecesario emitir pronunciamiento acerca de la solicitud de rectificación de escrutinio, sin pasar a revisar el fondo de la cuestión ${ }^{92}$.

Pero no obstante lo anterior, y atendido el hecho de que en un reclamo se señaló en forma específica y determinada el número de los presuntos votos nulos erróneamente escrutados, y considerando que ello, de ser efectivo, podía alterar fundamentalmente el resultado de la elección, y teniendo en consideración el deber del TRICEL de alcanzar adecuadamente la convicción plena sobre todos los antecedentes sometidos a su conocimiento, de oficio y haciendo uso de las facultades que la ley le concede, el Tribu-

\footnotetext{
Sentencia rol 11-90.
}

92 Sentencia rol 4-90. 
nal ordenó en varios casos practicar un nuevo escrutinio general y la calificación de la elección, por lo que decidió revisar públicamente los votos nulos y en blanco de alrededor de un tercio de las mesas objetadas, ordenándolo así como medida para un mejor acierto del fallo93.

En general, los agraviados deben presentar sus reclamaciones electorales para solicitar que se rectifique el escrutinio de votos practicado por los Colegios Escrutadores. Para que proceda la aceptación del recurso debe contener una serie de requisitos para su admisibilidad. Por eso es importante destacar que para alcanzar la anulación de alguna elección o plebiscito, es preciso que se establezca algún acto o vicio que ha de referirse exclusivamente a: 1) la designación o funcionamiento de las Mesas Receptoras o Colegios Escrutadores, o por procedimientos de las Juntas Electorales; 2) el escrutinio de cada Mesa o los que practicaren los Colegios Escrutadores; 3 ) los actos de la autoridad o de las personas que hayan coartado la libertad de sufragio; 4) la falta de funcionamiento de Mesas, y 5) la práctica de cohecho, de soborno o uso de fuerza y de violencia ${ }^{94}$.

En lo que respecta a la solicitud de rectificación de escrutinio, la Ley de votaciones señala que debe tratarse de omisiones o errores aritméticos. $Y$ tratándose de normas de Derecho Público, estas tienen la extensión que el legislador les ha dado, no pudiendo extenderse dichos preceptos a casos no contemplados expresamente en la Ley. Pues si se realizase, este nuevo recuento (no previsto en las normas reglamentarias del TCE) se le estaría dando más disposiciones al Tribunal de las establecidas por el legislador ${ }^{95}$.

Al final, el TRICEL decidió rechazar todos los recursos presentados bajo estas características, o sea que no cumplieran los requisitos de especificidad del agravio como: mesas receptoras, mal conteo de votos, anulación de votos, etc., y en cómo esos actos pudieron afectar su candidatura o la elección.

\footnotetext{
93 Sentencia rol 12-90.

94 Artículo 96 de la ley 18.700.

95 Sentencia rol 18-92.
}

\section{CONSERVACIÓN DEL ACTO PÚBLICO}

Un criterio y principio trascendente en las decisiones del TE es el de la conservación de la votación, por cuestiones de bien público. Esto significa que si no hay suficientes motivos para anular la votación y del análisis de cómo esas faltas pudieron afectar de manera sustancial la elección, poder dirimir, que aunque hayan existido infracciones en el proceso o en la manera en como se llevaron las elecciones, se debe conservar, si esas infracciones son menores. Por lo que si bien se les da recepción a esas impugnaciones, por estar bien fundadas y motivadas, esas violaciones no provocaran en el juzgador la aceptación de la nulidad de la votación de alguna mesa o de plano anular toda la elección.

Este criterio ha sido utilizado por el TCE, ya que a su parecer no cualquier infracción debe anular una elección, sino que el cúmulo o la gravedad de esas transgresiones, y la manera en como puedan las mismas actuar para contaminar de manera significativa la votación o comicio, y si no se comprueba la gravedad de esas infracciones, debe conservarse los actos electorales previos.

El TRICEL ha utilizado el principio de conservación de los actos públicos en materia de plebiscitos. El Tribunal juzgó que con base en lo señalado en el artículo 104 de la Ley Número 18.700, que si el hecho denunciado no tuvo influencia en el resultado del plebiscito, se debía rechazar el recurso, sin perjuicio de lo que el Tribunal de primera instancia pudiera resolver al proseguir la indagación sobre la responsabilidad penal de quienes decidieron la suspensión del acto electoral que se denunció ${ }^{96}$.

Otro ejemplo de lo anterior, acaeció cuando los ocurrentes estimaron que existía un alto número de cédulas estimadas nulas y el desconocimiento de la normativa que regula la materia por parte de los vocales de mesa hacían presumir que estos habían incurrido en errores reiterados y masivos en la calificación de los votos que perjudicaban a los candidatos. Asimismo, los ocurrentes señalaron que

96 Sentencia rol 9-88. 
"la rectificación y realización de un nuevo escrutinio cambiaría notablemente el resultado electoral, pues situaría al candidato como alcanzando la segunda mayoría relativa dentro de estos comicios" ${ }^{197}$.

Ellos fundaron su reclamo en la circunstancia de que en la totalidad de las mesas de las comunas que forman ese Distrito Electoral, los apoderados del partido Renovación Nacional concurrieron con implementos tales como hojas, planillas y carpetas con el logotipo de ese partido político, actuando como agentes propagandísticos del mismo.
Por lo que el TCE, infirió que el derecho a plantear reclamaciones electorales ${ }^{98}$ solo puede ejercerse cuando las irregularidades o defectos concretos en que estas tengan influencia con el "resultado general de la elección"99 o cuando de ellas se hubiere derivado la elección de un candidato distinto del que habría resultado electo a no mediar los incidentes reclamados. Ahora, si bien la ley autoriza reclamar la nulidad de las elecciones por actos que las hayan viciado, también la norma señala en forma expresa, cuáles son las causas que pueden esgrimirse como fundamento para solicitar dicha nulidad ${ }^{100}$.

En otro asunto, el TRICEL estimó la importancia de la conservación de la votación de la mesa receptora de votos, fue cuando las partes fundaron su alegato de nulidad en la circunstancia del delegado de la Junta Electoral, ordenó que se cerrara el local de votación, impidiendo el ingreso de público a dicho recinto, lo que importaría transgredir el artículo 96 de la Ley número $18.700^{101}$.

\footnotetext{
97 Sentencia rol 5-96.

98 Artículos 96, 97 y 104 inciso segundo de la Ley número 18.700 .

99 Sentencia rol 4-96.

100 Sentencia rol 12-92.

101 De acuerdo con el artículo precedente, en lo pertinente a esta clase de reclamos, solo se autoriza la anulación de escrutinios cuando los mismos se hubieren visto afectados por
}

En la resolución de este negocio, el TRICEL estimó que el hecho denunciado no se encuadraba en ninguna de las hipótesis legales, de modo tal que su ocurrencia no llevaba aparejada la nulidad de los escrutinios impugnados y que, a partir de los antecedentes presentados, se advirtió que el escrutinio se había practicado en presencia de los apoderados del partido político que reclamaba la nulidad, de modo que no se observó cómo la ausencia de público pudo significar un evento capaz de viciar el escrutinio. Por lo que el TCE rechazó declarar la nulidad de esa elección ${ }^{102}$.

Este principio también lo utilizó el TRICEL cuando un apelante presentó su reclamación electoral, solicitando la nulidad de la elección y del escrutinio, ${ }^{103}$ por las supuestas graves anormalidades ocurridas durante el acto eleccionario, las que consistieron en que no se le autorizó tener apoderados oficiales en los recintos de votación, lo que permitió que miles de votos con preferencia para su candidatura fueran anulados, otros agregados a los cómputos del candidato rival, y finalmente votos válidos de su candidatura fueron intencionalmente anulados. Este reclamo fue acompañado con diversos documentos y testimonios, que a su parecer daban veracidad a sus pretensiones ${ }^{104}$.

En otro caso, los apelantes solicitaban la nulidad de la elección, toda vez que por maniobras de los adherentes de su competencia política habían coartado la libertad de sufragio de los electores, debiéndose declarar la nulidad de la elección. Ellos fundaron su reclamo en la circunstancia de que en la totalidad de las mesas de las comunas que forman ese Distrito Electoral, los apoderados del partido Renovación Nacional concurrieron con implementos tales como hojas, planillas y carpetas con el logotipo de ese partido político, actuando como agentes propagandísticos del mismo. También, en el interior de

actos de autoridad que coartasen la libertad de sufragio, o sean constitutivos de cohecho, soborno, fuerza o violencia.

102 Sentencia rol 3-98.

103 Artículo 96 de la ley sobre Votaciones Populares y Escrutinios.

104 Sentencias rol 13-93, 14-93 y 23-93. 
los locales de votación, la Alcaldesa y una Concejal invitaban a votar por el candidato del partido político de su filiación, provocando gran alboroto. Finalmente, los apelantes señalaron que en muchas mesas se habían escrutado como nulos, sufragios que manifestaban una clara intención de voto a los candidatos de la Concertación por la Democracia.

Por lo que el TCE consideró que para coartar la libertad de votación de un ciudadano se requiere de actos de tal gravedad que puedan torcer su voluntad, llevándolo a sufragar en un sentido diverso al deseado y los hechos denunciados como constitutivos de tal acción-además de no estar debidamente acreditados- no constituían tal vicio. Más aún, los propios reclamantes señalaron que el actuar de las autoridades municipales en los locales de votación no pasaba más allá de un simple alboroto. Y en lo que la existencia de votos blancos y nulos en las mesas receptoras de sufragios es un hecho de común ocurrencia y nada indica, que tales sufragios tengan una intención de voto distinta a la manifestada. Por esos fundamentos, el TCE rechazó los reclamos interpuestos. ${ }^{105}$

En otro negocio, los apelantes fundaron su reclamación electoral, porque los escrutinios impugnados eran nulos porque: a) en ciertas mesas, el número de sufragios excedía al de firmas registradas; $b$ ) en otras, votaron electores cuya inscripción se habría cancelado; c) en algunas, votaron electores de otras mesas; d) en otras, se cometieron errores en el escrutinio; e) en algunas mesas, votó un elector que ya había sufragado en otra mesa; f) en dos mesas fusionadas no se levantó acta unitaria; y g) en tres actas no firmaron los vocales. ${ }^{106}$

Por lo que a juicio del TCE, los hechos descritos en ese reclamo no fueron fehacientemente acreditados $y$, en todo caso, los mismos no configuraban ninguna de las causales por las cuales podía anularse una elección.
Adicionalmente, el Tribunal consideró que los hechos, defectos 0 irregularidades que ocurrieron en el escrutinio de votos habían sido oportunamente corregidos durante la calificación y, en todo caso, carecen de fuerza suficiente para influir en el resultado general de la elección, de modo que con su solo mérito no procedía declarar la nulidad que se alegaba. En este caso, notamos tanto un exceso de formalismo en las causales para anular votación en las casillas, como el ánimo del juzgador de querer conservar la votación ya realizada, por lo que el TCE decidió rechazar este tipo de impugnaciones.

En otras ocasiones, hubo reclamaciones de nulidad de elección que contenían fundamentos apropiados, peticiones concretas y se acompañaron las pruebas respectivas. Estas demandas también se complementaron posteriormente, siendo motivo del pronunciamiento de fondo lo relativo a la plausibilidad de los fundamentos y peticiones, o a la convicción que produjeran las pruebas. Por lo que el TCE al revisar y valorar las probanzas acompañadas, pero ni aún ponderadas en conciencia lograron alterar la convicción del juzgador para anular la elección. Por lo que, el Tribunal declaró de manera definitiva e inatacable, desechar las reclamaciones planteadas por considerar que esos actos no afectaban a toda la elección ${ }^{107}$.

Por lo que para el TRICEL es inequívoco que, aún cuando objetivamente existiesen vicios de nulidad que resultasen efectivos, nada indica que de repetirse la elección en las mesas impugnadas, los ciudadanos que en ellas debieran sufragar nuevamente cambien la decisión electoral que ya expresaron, en un grado tal que permita al reclamante obtener en ellas los votos que le interesan ${ }^{108}$.

\footnotetext{
107 Sentencias rol 10-93 y 11-93.
}

108 Sentencia rol 61-92. 
De esta manera, el TCE determinó la improcedencia de esas pretensiones, pues aunque se probasen en

Esto tiene su

fundamento, porque

luego el candidato y

posible ganador, podría

decidir en su propia

causa y si sostiene

relaciones mercantiles,

él mismo podría

participar 0 autorizar el

pago por los servicios

prestados al municipio el proceso tales infracciones o equivocaciones, se debe considerar primero si es considerable el número de las mismas o la gravedad para modificar el resultado, por lo que el Tribunal estimó que no cualquier anomalía puede provocar la nulidad o repetición de una elección ${ }^{109}$.

Como hemos visto, el desarrollo de las elecciones puede generar irregularidades en las mesas de recepción, mismas que legalmente no son infracciones en materia electoral. En esas impugnaciones, el TCE estimó que no procedía el recurso de reclamación ${ }^{110}$. Porque con base en los antecedentes mostrados, esas infracciones electorales no constituían una reclamación de que debiera conocer el Tribunal, pudiendo ser los hechos denunciados la comisión de un delito de carácter electoral, por lo que el Tribunal devolvía el caso al Juez de Letras, para que continuara la tramitación y dictase en su oportunidad la resolución que fuese pertinente. Esto porque las reclamaciones que debe conocer el Tribunal Calificador no son otras que las que se indican en los artículos 96 y 97 de la Ley 18.700 , sobre situaciones que guardan relación con exigencias propias de la tarea electoral y del desarrollo de esa gestión, sin consideración a ninguna otra consecuencia que no sea el resultado de algún comicio realizado de acuerdo con el deseo de la voluntad de los electores.

\section{CONDUCTA DE LOS ACTORES POLÍTICOS EN CAMPAÑA}

El tema de la competencia electoral trae aparejado el observar cómo llevan su campaña política los candidatos. Las autoridades electorales han intervenido muy poco en el comportamiento del desarrollo de las elecciones, en este caso la regulación de la publicidad política.

Por ejemplo, en el caso de la elección de Senador en la décima región del año 1990. El candidato agraviado sostenía que se presionó indebidamente a los electores, coaccionando su voluntad, al plagarse la ciudad de Curicó, con unos panfletos (ilegalmente repartidos) con leyendas lesivas al reclamante, lo que consideró como el "asesinato de su imagen". Por lo que solicitó al Tribunal que procediera a la revisión y calificación de cada uno de los votos emitidos, rectificando los escrutinios, pues el justiciable estimó que se habían contabilizado equivocadamente votos nulos a su favor ${ }^{111}$.

Lo particular de esta impugnación fue la causal que se invocó, fundamentando su defensa por la "mala publicidad" que se difundió del candidato (causal, que no está contemplada en la normatividad). Pues en cuanto al analizarse un documento entregado entre las pruebas de descargo, se presentó un estudio consistente en un informe técnico suscrito por el periodista Manfredo Mayol titulado "Asesinato de Imagen", que en nada alteró las conclusiones del TCE, puesto que a consideración del órgano judicial, ese estudio no guardaba ninguna relación con los hechos y circunstancias del reclamo formulado, ya que se trataba de un trabajo teórico sobre el tema de la propaganda negativa y sus efectos, situación de orden meramente subjetivo. Por lo que el Tribunal rechazó en todas sus partes el reclamo interpuesto.

\section{NO SOSTENER RELACIONES CONTRACTUALES CON EL MUNICIPIO}

El sistema electoral chileno consigna la posibilidad de anular una candidatura si un candidato sostiene una relación contractual o un enfrentamiento judicial con el municipio en donde ahí mismo postula a algún cargo edilicio. Esto tiene su fundamento, porque luego el candidato y posible ganador podría decidir en su propia causa y si sostiene relaciones

111 Sentencia rol 13-90. 
mercantiles, él mismo podría participar o autorizar el pago por los servicios prestados al municipio; que si bien es cierto, se tiene como contrapeso a los concejales, debe considerarse que varias funciones como Alcalde las puede realizar sin la anuencia o consenso del resto del cabildo.

En este orden de ideas, en torno a una causal legal de inhabilidad para postular al cargo de concejal o alcalde, de manera que, aun cuando la parte petitoria de la misma no emplee expresiones destinadas explícitamente a provocar la declaración de inhabilidad, no puede caber duda alguna de que la intención del reclamante fue precisamente esa ${ }^{112}$. Por lo que el TCE consideró que no cabía ni abstracciones ni ambigüedades y menos podía estimarse que se estaba en presencia de una reclamación vaga o imprecisa, máxime cuando la abundante prueba rendida estaba orientada precisamente a acreditar el vicio sustancial que se invocó como fundamento de la misma, por lo que en este caso se comprobó la relación contractual entre el candidato vencedor y el municipio.

Otra de las causales para la cancelación de la inscripción del candidato es por sostener relaciones con el Estado en su calidad de prestador de servicios. Por ejemplo, un apelante señalaba que uno de los candidatos era administrador de una persona jurídica denominada Cooperativa de Consumo de Energía Eléctrica Chillán Limitada, compañía que había celebrado y mantenía contratos vigentes con el Estado: una concesión para establecer, operar y explotar en la Región del Bío Bío, las instalaciones de servicio público de distribución de energía eléctrica, contratos mercantiles y cauciones con el Banco del Estado, lo que lo inhabilitaba para ser candidato a Diputado.

En este caso, el TCE estimó que el artículo 54 número 8 de la Constitución establece que no pueden ser candidatos a parlamentarios las personas naturales y los gerentes o administradores de personas jurídicas que celebren o caucionen contratos con el Estado. Sin embargo, el reclamante no acreditó todos los requisitos exigidos por la disposición consti-

112 Sentencia rol 8-92. tucional, cuya aplicación invocaba para impugnar la declaración de candidatura.

Por lo que el Tribunal resolvió que quedaba suficientemente acreditado que la persona jurídica era administrador, pero que él no celebraba o caucionaba contratos con el Estado, por lo que se rechazó la inconformidad de esa candidatura ${ }^{113}$.

Como señalamos, la ley destaca que no se debe sostener una relación con el municipio, pues si este quedara elegido a un cargo dentro de la misma, podría comprometerse su imparcialidad y el manejo de la administración, pudiendo ser juez y parte. Sin embargo, en lo que se refiere a las relaciones comerciales que pueden sostener los candidatos a un cargo municipal, la ley esta-
El TCE señaló que no era el Municipio el ente jurídico que detentaba la condición de parte demandada, sino la Corporación Comunal de Desarrollo de Quinta Normal, persona jurídica distinta de aquel, razón suficiente para desestimar la apelación,

por lo que el Tribunal confirmó la inscripción de esa candidatura. blece como límite una

suma no superior a doscientas unidades tributadas mensuales ${ }^{114}$, por lo que si existiese una relación comercial, el TCE deberá cuantificar el monto de las operaciones financieras realizadas y pendientes entre el municipio y el candidato ${ }^{115}$.

También es requisito para postular a un cargo municipal, que el candidato no se encuentre en un juicio laboral por la misma comuna en que postula.

En un asunto particular seguido ante un Juzgado del Trabajo de Santiago, el candidato demandó a la Corporación Comunal de Desarrollo de Quinta Normal, al momento de postular para Concejal. Por lo que el TCE señaló que no era el Municipio el ente jurídico que detentaba la condición de parte demanda-

\footnotetext{
113 Sentencia rol 19-97.

114 Artículos 114 y 115 de la Ley número 18.695.
}

115 Sentencia rol 76-04. 
da, sino la Corporación Comunal de Desarrollo de Quinta Normal, persona jurídica distinta de aquél, razón suficiente para desestimar la apelación, por lo que el Tribunal confirmó la inscripción de esa candidatura ${ }^{116}$.

Entre los requisitos para postular a un cargo al Congreso o a la administración local, es el no contar con un cargo de representación de naturaleza gremial o vecinal, como lo preceptúa el artículo 54 número 7 de la Constitución Política. En un caso concreto, el TCE estimó que con los documentos acompañados en la apelación eran absolutamente suficientes para acreditar el cargo directivo de naturaleza vecinal del candidato a Senador. Por lo que el Tribunal decidió cancelar esa inscripción ${ }^{117}$.

\section{ACEPTACIÓN PARA REALIZAR UN NUEVO ES- CRUTINIO}

El escrutinio para el TCE ha sido entendido como el conjunto de actividades técnico-administrativas, cuya finalidad es determinar el sentido en que se ha manifestado la voluntad del cuerpo electoral. La calificación, en cambio, debe ser entendida, respecto a las elecciones, como la actividad de: "....apreciar o determinar las calidades de ellas y las circunstancias en que se ha realizado, a fin de establecer si se han seguido fielmente los trámites ordenados por la ley y si el resultado corresponde a la voluntad realmente manifestada por el elector, en una decisión libre y sin coacciones [...] establecer si la elección se ha verificado en conformidad a las disposiciones que la rigen y así poder declararlo, no solo quienes han resultado elegidos, sino también si lo han sido legítimamente"118.

La solicitud para la corrección de los resultados de la votación también fue advertido y resuelto por el TCE al analizar y revisar el resultado de la votación

\footnotetext{
116 Sentencia rol 97-96.

117 Esto lo realizó el TCE con base en lo dispuesto en el artículo 19 de la Ley Orgánica Constitucional sobre Votaciones Populares y Escrutinios. Sentencia rol 17-97, Alamiro Muñoz era al momento de la candidatura Presidente de la Junta de Vecinos "Villa Ayquina".

118 Considerando 14, Sentencia rol 117-92.
}

de una mesa ${ }^{119}$. Por lo que se procedió al mismo en varias ocasiones $y$, pudo establecerse la efectividad del fundamento de la reclamación que se había presentado ante el Tribunal, realizando en su caso la rectificación respectiva.

A pesar de las imposiciones administrativas por parte del TCE, hubo varios casos en que los apelantes cumplieron las formalidades tanto legales como las solicitadas por el Tribunal, vía auto acordado.

En estas apelaciones, el Tribunal Electoral Regional procedió a efectuar el escrutinio público de todas las mesas receptoras de sufragios referidas, abocándose a la revisión de los votos nulos de todas esas mesas, constatando y corrigiendo los errores cuando correspondía, pero sin que se detectaran hechos relevantes como para modificar los resultados de la elección, ni tampoco se acreditaron todos los hechos denunciados en la reclamación ${ }^{120}$.

En esta apelación se hizo la petición subsidiaria de anular la votación recibida en las mesas receptoras en razón de que habían funcionado todas ellas un menor tiempo que el ordenado por la ley, ya que no habrían permitido la libre recepción de sufragios. Pero, los reclamantes no acreditaron esta circunstancia y del análisis y observación que hizo el Tribunal de las correspondientes Actas de Escrutinio no se pudo colegir la existencia de la denunciada irregularidad, toda vez que en todas ellas se indica solo la hora en que comenzó el escrutinio. Por lo que el TCE, si bien realizó el nuevo escrutinio y se modificaron los datos previos, no cambió los resultados emitidos.

En otros negocios el TER (y el TCE confirmando la sentencia) simplemente aceptaba el recuento de los votos, porque los recurrentes habían cumplido con los requisitos de fondo y forma que establece el marco jurídico electoral, realizándose estas modificaciones, pero sin alterarse sustancialmente los resultados anteriores ${ }^{121}$.

\footnotetext{
119 Sentencia rol 16-88.

120 Sentencia rol 19-92.

121 Sentencia rol 92-00.
} 
La interpretación es fundamental cuando la norma no es clara o contiene algún vacío. En un caso particular se solicitaba un nuevo escrutinio, impugnando algunos votos declarados como nulos, porque las marcas que realizaron los votantes en las boletas electorales le favorecían y más por el estrecho margen de victoria del otro candidato.

En esta etapa del procedimiento y con ocasión del cumplimiento de las atribuciones del TER, un apelante señaló que los Colegios Escrutadores habían cometido varias irregularidades que consistieron en una interpretación errónea cuando procedió a contabilizar rayaduras o marcas que registraban algunas cédulas y que no consistieron justamente en la raya vertical que debe realizar el elector sobre la línea horizontal, 122 motivo por el cual, si se efectuase un nuevo escrutinio y corrigiéndose los errores del Colegio Escrutador, se proclamaban a otros como los candidatos elegidos, contabilizándole votos que, según la ley, eran votos en blanco ${ }^{123}$.

En este proceso, el TER al revisar las cédulas de determinadas mesas para contabilizar las preferencias de los electores procedió a contabilizar como votos válidos las cédulas en que parecía una marca, rayadura o señal distinta a la contemplada en la ley ${ }^{124}$. En este caso, se utilizó como criterio que una marca en el logo del partido político o un signo semejante, aunque no fuese una raya horizontal en la línea vertical del candidato era un voto válido.

Sin perjuicio de comprender la ardua labor del Tribunal Electoral Regional y su intención de interpretar, de algún modo positivo, la marca de un elector distinta a la raya vertical sobre la línea horizontal del candidato, produciría con este criterio un resultado distinto a tal punto que resultaba electo otro de los candidatos, por un estrecho margen de cinco votos.

Habiendo, entonces, una variación de lo reflejado que resultaba atendible y recomendable conocer el

\footnotetext{
122 Artículos 22, 24, 65 y 71 No.5 de la Ley número 18.700 sobre Votaciones Populares y Escrutinios.

123 Sentencia rol 14-92.

124 Artículo 71 número 5 de la Ley número 18.700.
}

dictamen final que sobre esta materia debería pronunciar el Tribunal Calificador de Elecciones, especialmente por la importancia que implicaba al terminar elegido un candidato diferente, sobre todo por el estrecho margen de votos, confirmó la sentencia del TER, modificando el resultado de la elección.

\section{DEMOCRACIA INTERNA DE LOS PARTIDOS PO- LÍTICOS}

La intervención del TCE en la vida y las decisiones de los partidos políticos no está prevista en la legislación electoral chilena ${ }^{125}$. Esto fue confirmado cuando en la participación electoral de un candidato en un subpacto se lesionaron sus derechos políticos, al excluírsele de las personas que fueron designadas para ser Concejales de la Comuna de Laja. Lo anterior fue motivo para solicitar al TER su intervención para dirimir los posibles agravios cometidos por el partido político.

En este negocio se solicitaba que se le incluyera del EI TER la registró dentro del grupo vencedor, pero faltaba el conteo para determinar a la lista ganadora de las elecciones municipales.

subpacto de la lista D Pacto

Unión por Chile, para poder salir electa como representante popular. El TER la registró dentro del grupo vencedor, pero faltaba el conteo para determinar a la lista ganadora de las elecciones municipales. Pero el TCE invalidó lo anterior, por considerar que esta atribución no estaba dentro de sus funciones ${ }^{126}$.

\section{FORMALIDADES DEL ESCRITO DE DEMANDA}

Una categoría que deseo señalar son las impugnaciones que tuvieran relación con el proceder del TRICEL. En diversas ocasiones el Tribunal, simplemente declaró "sin lugar" o "no ha lugar", debiendo consi-

125 Valladares, Carmen Gloria, "Sobre lo contencioso electoral y la jurisprudencia electoral en Chile", en El contencioso y la jurisprudencia electorales en derecho comparado, op. cit., p. 172.

126 Sentencia rol 1-96. 
derarse solamente la rectificación de escrutinios allí solicitada ${ }^{127}$.

Por ejemplo, en materia de plebiscitos, solo en una ocasión el TCE declaró "no ha lugar", a la reclamación interpuesta; pero esta resolución no contaba con la debida fundamentación y sin ninguna motivación del porqué de su resolución ${ }^{128}$.

En otras ocasiones, las denuncias no tenían ninguna prueba para demostrar sus aseveraciones, tampoco se solicitó ni rindió ninguna información o contra información tendientes al mismo fin $^{129}$. Porque según las normas electorales, el escrito de reclamación debe ser fundado, contener peticiones concretas y señalar o acompañar los medios probatorios que le sirven de fundamento; debiendo, en lo posible, ser una sola presentación para cada distrito o circunscripción electoral. Por esos fundamentos, el Tribunal no admitió varios reclamos interpuestos, declarándolos inadmisibles.

Otro elemento que se presentó para solicitar la realización de nuevo escrutinio de la votación fue la conducta de los responsables de las mesas receptoras. Sobre este tema, tenemos la apelación 3-92 que se fundamentaba en los antecedentes electorales que personalmente obtuvo el compareciente de los Presidentes de las mesas, y ante numerosos testigos que le acompañaban, como medios de prueba.

Sin embargo, ninguno de los actos impugnados contenía los elementos oficiales de la elección como son el funcionamiento de las mesas, de los Colegios Escrutadores o el Acta de Escrutinios practicados en ellos.

En particular, la petición de efectuar por el Tribunal un recuento de todos los votos obtenidos por las candidaturas, incluidos los votos en blanco y nulos, sin indicar las irregularidades, y las mesas o actuaciones en que se hubieran cometido irregularidades, padecía a vista del TCE de vaguedad e imprecisión,

\footnotetext{
127 Sentencia rol 1-93.

128 Sentencia rol 10-88.

129 Sentencia rol 2-90.
}

pues la petición "adolece de falta de especificación, lo que la hace inadmisible, atendidas la naturaleza y finalidad de tal derecho y que el artículo 97 de la Ley 18.700 dispone que dicho recurso procederá para rectificar escrutinios en que se haya incurrido en omisiones o en errores aritméticos, lo que presupone especificar las omisiones o los errores aritméticos que la justifican en derecho. Pretender que puede exigirse al Tribunal Electoral Regional hacer, por sí mismo, los escrutinios de todas las Mesas, de varones y de mujeres, de una Comuna (o de todas las de la Región) sin más requisito que formular oportunamente tal solicitud ante quien corresponda, es desvirtuar totalmente el sentido y alcance de las Reclamaciones Electorales, así como del correspondiente proceso del Escrutinio General y de la Calificación de Elecciones, normado en el Título $\mathrm{V}$ de la citada Ley número $18.700^{\prime 130}$, puesto que se limitaba a una denuncia general del escrutinio de los votos emitidos, por lo que se rechazaron todos los recuentos si no se fundaba y motivaba propiamente, del por qué debía elaborarse tal escrutinio y sobre todo demostrar el supuesto agravio, pues en caso de hacer este recuento equivalía según al TCE, atribuirle una función fiscalizadora ajena a sus facultades jurisdiccionales, por lo mismo declaró "no ha lugar" o como inadmisibles esas apelaciones.

Además, de que el artículo 95 de la Ley número 18.695 en relación con el Título IV y V de la Ley Orgánica sobre Votaciones Populares y Escrutinios y el numerando cuarto del auto acordado del TCE, ${ }^{131}$ establecían que el escrito de reclamación debía ser fundado, contener peticiones concretas y señalar o acompañar los medios probatorios que le sirven de fundamento ${ }^{132}$

Por lo que podemos observar, la anterior reglamentación tenía como objeto preciso el evitar constituir a estos tribunales en una verdadera tercera instancia de recuento de votos efectuado primeramente por las respectivas mesas receptoras $y$, con posterioridad por los Colegios Escrutadores.

\footnotetext{
130 Sentencia rol 6-92.

131 Diario Oficial del 5 de mayo de 1992.
}

132 Sentencia rol 10-92. 
El excesivo legalismo por parte del TRICEL, por la no satisfacción puntual de los requisitos de la demanda en cuanto a la forma, sin dar ninguna prevención, puede provocar que se desechen las apelaciones, sin estudiar el fondo de la cuestión. Por ejemplo, en la apelación de un reclamante se limitó a señalar que "hubo errores y omisiones" en diversas Mesas receptoras en Coquimbo y en Tongoy ${ }^{133}$.

En este caso, el ocurrente no explicó ni indicó en qué consistieron tales errores $u$ omisiones, ni menos de qué manera tales supuestos influyeron en el resultado del escrutinio en cada una de las mesas señaladas. Además de que no se allegaron al Tribunal todos los elementos probatorios atingentes a los hechos que se aducían en la reclamación. La ambigüedad era tan manifiesta para el TCE, que no le fue posible ni siquiera deducir qué fue lo que se omitió, ni la naturaleza de esos errores que, sin duda, como mencionó el Tribunal: "solo existen en la imaginación del reclamante"134. Por lo que la máxima autoridad electoral se encontró en la imposibilidad de poder resolver este tipo de asuntos, ya que no resultaba posible determinar el fundamento en virtud del cual se sostenía la existencia de errores u omisiones, desde el momento que no fueron precisados ni señalados debidamente.

En general, se desecharon las demandas que no cumplían los requisitos de forma que señalan las normas electorales y los autos acordados emitidos por el TCE. Esta falta de requisitos de la demanda conllevó a la plena y directa inadmisibilidad del recurso por parte del Tribunal Electoral ${ }^{135}$.

Un punto que debo mencionar es que los apelantes en diversas ocasiones al tener una sentencia en contra por parte del TER presentaban sus recursos de apelación. Sin embargo, después de declarada en autos su admisión por el TCE, los actores no continuaban con el proceso, por lo que el Secretario re-

\footnotetext{
133 Sentencia rol 1-92.

134 Sentencia rol 2-92.

135 Sentencias rol 8-90, 9-90, 10-90, 14-90, 15-90, 16-90 y 17-90.
}

lator en uso de sus facultades declaraba desierto el recurso de apelación ${ }^{136}$.

Por último, en cuanto en materia procesal, el TRICEL aceptó en varios asuntos realizar nuevos escrutinios, con base en el mérito del resultado que arrojó el escrutinio público ${ }^{137}$. Empero, el apelante posteriormente se desistió de la demanda, por lo que el Tribunal decidió dar por concluido el proceso de impugnación, sin revisar ninguna otra cuestión.

\section{INCOMPETENCIA LEGAL}

El mecanismo del TCE para impartir justicia es primero estudiar los requisitos de forma del escrito de demanda, para posteriormente observar si el asunto presentado está dentro de tiempo y si es de su competencia. Esta ha sido la conducta jurisdiccional del Tribunal.

En materia de plebiscitos, la mayoría de las inconformidades fueron canalizadas al Juzgado del Crimen correspondiente por diversas faltas a la ley de Votaciones y Escrutinios Populares, en estos casos los magistrados electorales del TE consideraron que no estaba dentro de su competencia su resolución ${ }^{138}$.

Por ejemplo, en la causa 1-88 se acusó a un miembro de la Mesa Receptora de no devolver oportunamente los útiles electorales y el Acta con el resultado de la votación, hechos que a juicio del TCE eran competencia exclusiva del Juez del Crimen correspondiente ${ }^{139}$.

Otro hecho que se denunció, en materia plebiscitaria, fue que se instaló la Secretaría de un Partido Político en un local a menos de doscientos metros de una Mesa Receptora de Sufragios, por lo que el

36 Sentencias rol 17-92 y 3-96.

137 Sentencias rol 4-98 y 5-98.

138 El TCE consideró que los hechos acaecidos no eran propios de su competencia y fundó sus sentencias con base en lo dispuesto en los artículos 78, 133, 138, 137 y 144 de la Ley Orgánica Constitucional de Votaciones y Escrutinios.

139 Artículo 134 de la Ley Orgánica Constitucional sobre Votaciones Populares y Escrutinios. 
TCE estimó que no era asunto del que correspondía entender al Tribunal, sino que era competencia del Juzgado del Crimen respectivo, por tener relación con una posible infracción penal ${ }^{140}$. Otro asunto fue porque no remitieron en su oportunidad los documentos que debieron elevar al Colegio Escrutador correspondiente ${ }^{141}$.

En otros casos, el TRICEL estimó que los hechos acaecidos no lograron los caracteres de infracción ${ }^{142}$; i.e. si se tiene en cuenta que la devolución de los documentos electorales se hizo por envío de co-

"De los antecedentes

reunidos en esa

denuncia y de

los que poseía el

Tribunal, constaba

que el resultado del

Colegio Electoral

se había realizado

oportunamente y

que en el interior de

la caja de sufragios

correspondiente estaba

el sobre con "las

cédulas no usadas 0

inutilizadas y los talones

de las emitidas"

rreos equivocadamente al Director del Servicio Electoral.

Esto también acaeció en el caso 18-88, porque los supuestos agraviados observaron que los vocales de la Mesa Receptora de Sufragios no cumplieron con la obligación de cerrar, lacrar y firmar por el lado del cierre el sobre de "Cédulas no usadas o inutilizadas y talones de las emitidas", y que también, el Delegado de la Junta Electoral de esa misma circunscripción no había remitido a la Junta Electoral el sobre de las Mesas en referencia. Pero, teniendo presente que de los antecedentes reunidos en esa denuncia y de los que poseía el Tribunal, constaba que el resultado del Colegio Electoral se había realizado oportunamente y que en el interior de la caja de sufragios correspondiente estaba el sobre con "las cédulas no usadas o inutilizadas y los talones de las emitidas", y que todo se había enviado en las condiciones que exige la ley, por lo que los hechos de la denuncia no

\footnotetext{
140 Sentencia rol 4-88.

141 Sentencia rol 8-88.

142 Sentencias rol $17-88$ y $19-88$.
}

lograron comprobar la perpetración de una infracción que debiera ser sancionada.

Otro rubro importante, donde determinaron su capacidad de poder resolver una causa no contemplada en la ley, fue cuando ante la falta del Alcalde se pudiera revisar la votación interna del cabildo de los Concejales para elegir al nuevo presidente municipal, lo cual no está establecido en las normas directamente, pero sí la calificación de los Concejales.

Sobre este tema, el TCE consideró que sí puede intervenir para calificar las votaciones de los Concejales, cuando se deba seleccionar a un Alcalde de entre ellos mismos. Aquí hay que recordar que el Concejo puede decidir quién sustituirá al Alcalde en caso de ausencia, el punto es saber si las elecciones del cabildo pueden ser revisables por el TER. En este asunto, los recurrentes fundamentaron su reclamación en que no habiéndose logrado la mayoría absoluta en la primera votación, producida la segunda, el Secretario Municipal declaró ilegible un voto y seguidamente lo declaró nulo ${ }^{143}$.

En primera instancia, el TER se calificó "incompetente" para juzgar, pues no se encontraba dentro de sus atribuciones legales, con base a que las normas relativas al funcionamiento de ese Tribunal se encuentran regidas por el principio establecido en el inciso $2^{\circ}$ del artículo $7^{\circ}$ de la Constitución en cuanto que: "Ninguna magistratura, ninguna persona ni grupo de personas puede atribuirse, ni aun a pretexto de circunstancias extraordinarias, otra autoridad o derechos que los que expresamente se les hayan conferido en virtud de la Constitución o las leyes", y no existía disposición legal alguna que le otorgase competencia para conocer de cuestiones que se suscitaran en las actuaciones de los concejales ya elegidos, salvo aquellas que expresamente así lo disponen, entre las que no se encontraba la que fue motivo de la reclamación ${ }^{144}$.

Sin embargo, el TCE consideró que corresponde a los Tribunales Electorales Regionales efectuar "el escrutinio general y la calificación de las elecciones

\footnotetext{
143 Sentencias rol 6-92 y 7-92.
}

144 Sentencia rol 2-93. 
municipales", según la Ley Orgánica de Municipalidades y conforme al procedimiento contemplado en ella deben determinar el nombre de los Concejales que resultan definitivamente electos $y$, en su caso particular, proclamar el Alcalde si este se encuentra en la situación prevista en el inciso $1^{\circ} \mathrm{del}$ artículo 115 de la Ley de municipalidades. Asimismo, el TRICEL estimó que corresponde a los Tribunales Electorales Regionales efectuar "el escrutinio general y la calificación de las elecciones municipales". Pues, en la ley de municipalidades se establecen las normas a que deben sujetarse los concejales electos para la elección del Alcalde de cada comuna en la primera sesión constitutiva del respectivo Concejo Municipal.

Por lo que el Tribunal Electoral Central sentenció que el TER estaba facultado para revisar los actos del Concejo, en cuanto a las elecciones a su interior para elegir al nuevo Alcalde.

Sobre el mismo rubro para la selección del nuevo Alcalde, el TCE estableció un mecanismo para decidir en caso de desempate entre los Concejales que postulan para ser Alcaldes vía cabildo.

Esto, porque la ley no contempla qué sucede si ambos candidatos son del mismo Pacto, por lo que el TER decidió con base en la interpretación, que este caso encuadraba en la norma de hermenéutica legal -de aplicación general en todo el ámbito del Derecho- expuesta en el inciso primero del artículo 22 del Código Civil, que establece:

"El contexto de la ley servirá para ilustrar el sentido de cada una de sus partes, de manera que haya entre todas ellas la debida correspondencia y armonía"; que permite considerar la situación de los subpactos electorales en el mismo rango jurídico que el artículo 115 de la ley de municipalidades que asigna a la lista que hubiere obtenido la mayor votación. Por lo que se resolvió que el candidato con más votos como Concejal debía ser reconocido como el nuevo Alcalde ${ }^{145}$. Asimismo, en caso de no llevar estas elecciones municipales internas conforme a lo que

145 Sentencias rol 1-93 y 3-93. estipula la ley de municipalidades, el TER puede solicitar que se repitan esas elecciones ${ }^{146}$.

Por último, en el tema de impugnación de comicios analizaremos la única elección anulada en su totalidad por el TCE. Esto acaeció cuando el candidato Erick Vergara Moreno dedujo la reclamación de nulidad y rectificación de escrutinios, en la elección para Alcalde a la Comuna de
El TCE consideró que corresponde a los Tribunales Electorales Regionales efectuar "el escrutinio general y la calificación de las elecciones municipales.
Talcahuano en el $2004^{147}$. Por lo que el TCE al estudiar los argumentos y la adminiculación de los hechos con las pruebas decidió acoger la apelación para anular la elección. Entre las pruebas ofrecidas, se presentó el escrutinio público de 77 mesas, detectándose numerosas y graves anomalías de las que dio cuenta en el acta respectiva.'

Por lo que el TCE, al revisar este asunto, sentenció que: "como lo señala el artículo $5^{\circ}$ de la Constitución, la elección de las autoridades y representantes constituye la manera en que la Nación ejerce -por vía directa- la Soberanía que en ella reside. Es por ello que los actos eleccionarios deben estar revestidos de la mayor pureza y presididos siempre por la buena fe. Cualquier desviación que afecte tales principios no solo puede traer consigo una alteración de la voluntad popular, la que es de la esencia de régimen democrático, sino también una grave corrosión de la Fe Pública que, necesariamente, deben tener los ciudadanos en aquellos a quienes han elegido como conductores de los destinos de la comunidad, en sus distintos ámbitos" ${ }^{\prime 148}$.

Pues en esta elección era incontrovertible que se estaba en presencia no de simples errores o de justificables omisiones, sino de actitudes claramente dirigidas a distorsionar la voluntad del electorado:

\footnotetext{
146 Sentencia rol 11-92.

147 Sentencia rol 177-04.

148 Considerando $8^{\circ}$ de la Sentencia rol 117-04.
} 
"...debe considerarse, en primer término, que ni la Ley número 18.700 ni ninguna otra que tenga relación con los procesos eleccionarios hace referencia a la posibilidad de darse las anomalías que ocupan la atención de este Tribunal y, por ende, no contienen tampoco la forma en que ellas deben ser remediadas" ${ }^{149}$.

Frente a este vacío de la ley y no siendo ni jurídica ni lógicamente posible desatender las graves irregularidades que se habían comprobado, el TCE consideró que el problema debía ser resuelto conforme a los principios generales del derecho y a la equidad $^{150}$.

Por lo que era imposible para el TCE conocer cuál fue, en realidad, la preferencia asignada por los electores a los candidatos en contienda. Por lo que a juicio del Tribunal, "la lógica y la equidad natural aconseja prescindir en la calificación de la elección,

La repetición de la elección en las mesas

aludidas importaría

dejar entregada a la

voluntad de un reducido

número de sufragantes

(2,85\% del total de

sufragios emitidos) la

decisión final respecto

de quién ocuparía el

cargo de Alcalde en la

comuna de Talcahuano. de los resultados espurios que fueron consignados en las actas de tales mesas"151.

Otro factor fundamental para esta decisión fue la escasa diferencia de sufragios que existía entre los candidatos. Pues la repetición de la elección en las mesas aludidas importaría dejar entregada a la voluntad de un reducido número de sufragantes (2,85\% del total de sufragios emitidos) la decisión final respecto de quién ocuparía el cargo de Alcalde en la comuna de Talcahuano, quedando abierta la posibilidad de que dichos electores pudieran ser

149 Inciso 11 de la Sentencia rol 117-04.

150 Artículo 24 del Código Civil.

151 Mesas números 5 de mujeres y 1 y 4 de varones de Medio Camino y en las Mesas números: 76, 80, 107, 109, 111, $112,113,129$ y 129 de mujeres y 101 de varones de Talcahuano Centro. objeto de cualquier tipo de presiones, con manifiesta vulneración de la pureza del acto eleccionario ${ }^{152}$.

Además, aun cuando ello no incide en el resultado de la calificación y escrutinio general, se dejó constancia de que en algunas de las mesas revisadas había una casi nula abstención y que, conjuntamente, en la revisión de los cuadernos de firmas se advirtió sospechosas similitudes entre las estampadas en los casilleros correspondientes a distintos electores, irregularidad que, por su frecuencia, no podía dejar de consignarse.

Por lo anterior, el TCE sentenció: "que las causales de nulidad detectadas en el proceso consistieron en la manipulación del escrutinio de ciertas mesas receptoras de sufragios o en el escrutinio de los colegios escrutadores -o recogidas por estos- atribuibles presuntivamente a la conducta de los vocales de aquellas mesas en que existe diferencia de número de cédulas electorales, para Alcaldes y para Concejales"153. Así como, "la indebida manipulación del escrutinio de las mesas receptoras de sufragios, no faculta a la autoridad electoral para considerar esa información electoral, que ya resulta poco veraz y distorsionada"154.

Asimismo, el TRICEL advirtió que hubo: "una dudosa nula abstención y sospechosas similitudes de firmas, que hacen aumentar el cuadro general de irregularidades que han determinado una convicción de que cualquier revisión y resultado de la dicha elección de Alcalde no representaría una real voluntad del electorado"155.

Por consiguiente, el TCE al calificar la calidad de pureza, transparencia y descontaminación que permitiera expresar un resultado legítimo, estimó ineludible declarar nulo el proceso electoral referido, por lo que ordenó se realizara un nuevo proceso electoral, destinado a elegir a la máxima autoridad edilicia de la comuna de Talcahuano.

\footnotetext{
152 Inciso 14 de la Sentencia rol 117-04

153 Inciso 21 de la Sentencia rol 117-04.

154 Inciso 22 de la Sentencia rol 117-04.

155 Considerando $23^{\circ}$ de la Sentencia rol 117-04.
} 
Hasta aquí hemos examinado las impugnaciones de los resultados de las elecciones, por lo que pasaremos a revisar las inconformidades que han presentado los partidos políticos por diferentes motivos.

\section{RECLAMACIONES DE LOS PARTIDOS POLÍTICOS}

Los partidos políticos son un producto de la fórmula democrática de gobierno, que supone la pluralidad de corrientes políticas e ideológicas que coexisten en una sociedad, deben y pueden expresarse intentando ganar adhesión de la voluntad ciudadana mayoritaria, la cual es la fuente legítima para ocupar los puestos de gobierno y legislativos ${ }^{156}$.

Por lo que los partidos políticos son los puentes necesarios entre la sociedad civil, el Estado y el gobierno, son los organismos necesarios para capacitar a los ciudadanos en el ejercicio de los cargos públicos, en la formulación de proyectos de gobierno, porque para que haya un buen gobierno, todos los partidos deben ser corresponsables de la conducción correcta de la sociedad ${ }^{157}$.

Como señalamos previamente, el TRICEL no tiene competencia para resolver asuntos internos de los partidos políticos. Sin embargo, sí está facultado para anular, confirmar o modificar las resoluciones emitidas por el Servicio Electoral, en relación con los partidos políticos.

En el primer caso que se expondrá, el TCE revisó la sentencia del SERVEL, porque existía semejanza en los nombres de dos partidos políticos. Esto sucedió en el caso del Partido Radical de Chile, en el que se reconoció el derecho de que una corriente escindida del partido pudiera constituirse como partido político, pero con un nombre y siglas distintas al primer partido que obtuvo su registro ante notario y que goza del mismo desde el momento de su constitución ${ }^{158}$.

156 Becerra, Ricardo, et al, La reforma electoral de 1996, Ed. FCE, México, 1997, p. 56.

157 González Durán, Carlos, "Justicia electoral y resolución de conflictos", op. cit., p. 205.

158 Sentencia rol 1-88.
La semejanza entre las siglas y el nombre de los partidos de reciente creación, también sucedió en la causa 1-94. En este recurso de queja se inconformaron por la similitud fonética y gráfica con el nombre y sigla del partido político en formación denominado "Partido Humanista de Chile", pero, el TCE consideró que no existía falta o abuso reparable por esta vía, por lo que desestimó el recurso presentado.

Otro problema con el uso y propiedad del nombre, acaeció cuando el Partido Demócrata Cristiano apeló la decisión del SE, porque en las cédulas electorales aparecía solo con el nombre "Demócrata Cristiano", por lo que los representantes presentaron su recurso para que se modificaran las boletas con su nombre que aparecía en el SERVEL, lo cual fue rechazado por el TRICEL, por considerar que esta denominación era única y que los electores podrían identificarla fácilmente, además de que el concepto "Partido" es ya de uso tradicional e histórico, y que en nada alteraba la identificación política del interesado, utilizándose así en la propaganda de la prensa nacional; por lo que el Servicio Electoral también lo estaba aplicando, en igualdad para todos los candidatos ${ }^{159}$.

Otro caso acaeció cuando el Partido Social Democracia Chilena tuvo dos Tribunales Supremos, por lo que se solicitó la intervención en primera instancia del Director del SE, para la solución de sus conflictos internos $y$, posteriormente, la intervención del TCE. ${ }^{160}$

El hecho de que el diferendo en examen haya llegado al extremo que en el Partido Social Democracia Chilena existieran dos Tribunales Supremos de distinta composición, por lo que a consideración del propio TCE: "mal cabría dotar al Tribunal de una competencia que su propia Ley Orgánica le desconoce. Además, se desprende nítidamente de la cita de la historia fidedigna del establecimiento de la Ley Orgánica en referencia, que el TCE solo tiene competencia para fallar las reclamaciones que tengan relación con la generación defectuosa del Tribunal Supremo de un Partido Político, todo ello de con-

159 Sentencia rol 102-89.

160 Sentencia rol 3-88 (recurso de queja). 
formidad al procedimiento establecido en la ley de Partidos Políticos"161.

El TCE rechazó los
intentos legales para
dirimir discusiones
intrapartidarias, por
no estar habilitado por
ley y solo conocer en
casos de la correcta
constitución del
Tribunal Supremo,
mas no para calificar
sus actuaciones,
confirmando la
independencia de los
partidos políticos y la
no intromisión en su
vida interna.

Continuando con el tema de las disputas al interior de los partidos políticos, la Ley de partidos políticos no atribuye al Presidente del Tribunal Supremo de cualquier partido, como tampoco a uno u otro "quórum" de mayoría que exista o se produzca entre sus integrantes, el derecho a ocurrir ante el TCE reclamando la nulidad de cualquiera de sus propias actuaciones o decisiones. Porque el artículo $19^{\circ}$ número 15 de la Constitución Política prescribe que los Estatutos de los partidos políticos "deben contemplar las normas que aseguren una efectiva democracia interna", exigencia que, en defecto o silencio de tales estatutos, como ocurrió respecto con los estatutos aprobados por el Partido Nacional, por lo que para modificarse se requiere la aprobación de cierto porcentaje de miembros del Consejo General o de la representación parlamentaria, en su caso ${ }^{162}$.

Los recurrentes consideraron que no existía motivo alguno para creer que sus elecciones pudieran quedar marginadas del sistema de justicia electoral, puesto que lo contrario significaría conferir a los partidos un privilegio especial en relación con los demás cuerpos intermedios de la sociedad, que los exceptuaría de someterse a la autoridad jurisdiccional que la propia Constitución Política ha instaurado, más aún si se tiene en cuenta el interés social comprometido, en orden a que las directivas de los partidos políticos sean verdaderamente representativas de sus bases y que en su generación se

\footnotetext{
161 Sentencia rol 4-88 (recurso de apelación).
}

162 Sentencia rol 13-00. cumplan las formalidades legales y estatutarias que precisamente las dotan de esa legitimidad.

Además, la circunstancia de que los artículos 56 y siguientes de la Ley Orgánica Constitucional de los Partidos Políticos se ocupa de regular los Tribunales para conocer las infracciones a la reglamentación interna, pero esto no otorga competencia para esos efectos a los Tribunales Electorales Regionales, y de manera excepcional en el artículo 57, se confiere atribuciones al Tribunal Calificador de Elecciones para los efectos de conocer determinadas apelaciones $y$, en única instancia, para conocer de las reclamaciones que "tengan relación con la generación defectuosa del Tribunal Supremo de un Partido Político". Por lo que el TCE rechazó los intentos legales para dirimir discusiones intrapartidarias, por no estar habilitado por ley y solo conocer en casos de la correcta constitución del Tribunal Supremo, mas no para calificar sus actuaciones, confirmando la independencia de los partidos políticos y la no intromisión en su vida interna ${ }^{163}$.

Siguiendo con el tema de la independencia interior de los partidos políticos, nuevamente el TCE dejó sin juzgar (por incompetencia legal), los mecanismos de publicidad del partido político y declaró que el Tribunal Supremo del Partido debía hacer cumplir con las formalidades del proceso eleccionario interno. En este asunto, se solicitó la nulidad de la elección del Partido Radical Social Demócrata destinada a la renovación de los Consejeros Regionales y de la Directiva Central, fundada en la circunstancia de haberse omitido el cumplimiento de diversas formalidades de publicidad de dicho acto eleccionario. Asimismo, se señaló que la Junta Nacional Electoral

163 Sentencia rol 80-06. También se presentó un recurso de hecho para desconocer las elecciones para elegir a la directiva y consejeros distritales, fallándose en el mismo sentido de la incompetencia del TCE (Sentencia rol 82-06). Al igual que en la nulidad de la elección para la directiva comunal de Viña del Mar del Partido Demócrata Cristiano, se declaró incompetente el TCE para resolver disputas internas, siendo esto tarea del Tribunal Supremo. Aquí cabe señalar que al Tribunal Calificador de Elecciones solo le corresponde conocer de las reclamaciones que tengan lugar con la generación defectuosa del Tribunal Supremo de un partido político. (Sentencia rol 10-07, lo mismo resolvieron en la causa 59-07). 
del partido no habría designado con la debida anticipación los lugares de votación ni a las comisiones receptoras de sufragios ${ }^{164}$.

En este caso, el TCE estimó que las formalidades de publicidad que se exigen respecto de una convocatoria a elecciones tienen por finalidad que quienes tienen derecho a participar en ella sea como electores o como candidatos, se informen con la debida anticipación de la oportunidad en que se realizará el acto eleccionario, así como de los demás trámites y plazos involucrados en el respectivo proceso, a fin de hacer efectivo ese derecho.

El TRICEL estimó que el artículo 28 de la Ley de Partidos Políticos, señala que estas entidades (partidos políticos) tendrán un Tribunal Supremo y entre sus facultades (letra e) se establece la de controlar el correcto desarrollo de las elecciones partidistas y dictar las instrucciones generales o particulares que para tal efecto correspondan. De manera que por ley, son los Tribunales Superiores de los Partidos Políticos los que tienen competencia para "controlar" el correcto desarrollo de las elecciones y votaciones pendientes.

En cuanto a la extinción de un partido político por parte del SERVEL, el TCE estimó que cabía concluir que "el Partido Humanista desde el momento de su inscripción cumplió de manera oportuna con las formalidades legales que establece la Ley de Partidos Políticos, por lo que no se dio la condición para que procediera aplicar sanción por omisiones reglamentarias en este sentido" 165 .

Empero, el máximo órgano jurisdiccional electoral consideró que el Director del Servicio Electoral al dictar la Resolución reclamada había incurrido en una falta de apreciación de los factores que constituían la causal de disolución que se reclamaba, situación que debió ser enmendada por la vía de los recursos interpuestos. Por lo que el TRICEL falló a favor del Partido Humanista, por lo que pudieron conservar su registro.

\footnotetext{
164 Sentencia rol 87-00

165 Sentencia rol 5-88.
}

En el siguiente apartado estudiaremos las inconformidades de los partidos políticos por las sanciones impuestas por el Servicio Electoral, en cuanto al rubro de sus infracciones a la ley sobre transparencia, límite y control del gasto electoral.

\section{GASTO ELECTORAL}

El manejo de los recursos fue tema de conflicto entre el SE y el Partido Socialista de Chile, porque no cumplían los requisitos de fondo y forma, dando el TCE un plazo adicional para cumplir con sus obligaciones contables ${ }^{166}$.

En otra imputación hecha contra una resolución del Servicio Electoral en el tema del manejo de la contabilidad del Partido Socialista de Chile, esto acaeció cuando supuso la autoridad administrativa electoral que este partido estaba coludido con sus proveedores, al aceptar que determinados respaldos contables, tales como facturas por ventas o servicios fueran entregados por los proveedores con varios meses de atraso a la época del pago ${ }^{167}$.

Al considerar este asunto, el TCE lo desechó debido a que dichas infracciones habían sido cometidas por los proveedores y que el Partido Socialista de Chile había tratado de obtener la entrega de la documen-

166 Sentencia rol 5-97.

167 Sentencia rol 45-97. Sobre este mismo problema contable del Partido Socialista, el Director del Servicio Electoral rechazó el Balance anual presentado por el Partido Socialista de Chile correspondiente al ejercicio del año 1997 conforme al mérito del "Informe de Revisión Contable", dio cuenta de las siguientes infracciones e irregularidades contables: "A) Se giran cheques sin tener facturas y/o boletas de respaldo. B) Se hacen pagos a proveedores extendiendo cheque a nombre de una persona distinta del proveedor. C) No se exige al proveedor la entrega oportuna de la factura al cancelar los cheques, posponiendo u omitiendo el correspondiente impuesto al valor agregado. D) Se paga honorarios contra boleta de servicios que ha sido anulada. E) Los impuestos retenidos no son pagados a la Tesorería General de la República. F) Se otorgan préstamos al personal que no han sido recuperados". Pero al analizar y resolver el TRICEL, con lo relacionado y de conformidad a lo dispuesto en los artículos 34, 51 y 56 de la Ley sobre Partidos Políticos, y encontrándose subsanados y justificados los reparos formulados por el Director del Servicio Electoral al ejercicio tributario 1997 por el Partido Socialista de Chile, el TCE decidió rechazar la denuncia interpuesta. Sentencia rol 23-98. 
Los Partidos políticos

sancionados

consideraron que el SE

sólo está facultado para

practicar un examen

formal del movimiento

contable, toda vez que el

Título V de dicha Ley que

trata el Financiamiento

de los Partidos Políticos tación, por lo que no podía atribuírsele negligencia inexcusable, ni deducirse que en las infracciones referidas existió participación dolosa del presidente $y / o$ del tesorero del Partido. Por lo que el TRICEL consideró que respecto de algunas de las partidas objetadas, la ausencia de la documentación de respaldo se debió a faltas cometidas por los proveedores o prestadores de servicios, al no entregar en la oportunidad correspondiente las facturas debió desestimarse esta consideración que disponen los artículos 52 y siguientes de la Ley sobre Impuesto a las Ventas y Servicios, al establecer que la obligación tributaria de emitir la correspondiente factura o boleta al momento de recibir el pago es materia del prestador.

Por las razones antes expresadas, el Tribunal concluyó que no era posible aceptar que el Partido Socialista de Chile había incurrido en la infracción sancionada en el artículo 51 de la Ley Número 18.603 al no conservar suficientemente la documentación que respaldase las anotaciones practicadas en los libros de contabilidad. Por lo que se resolvió rechazar la denuncia hecha por el Director del Servicio Electoral.

El control del financiamiento de los gastos electorales proviene de una ley reciente, que tiene como misión la transparencia, límite y control del gasto electoral. Esta ley señala qué es un gasto electoral, la contabilidad que se deberá llevar de los mismos gastos, la rendición de cuentas al Servicio Electoral y las sanciones, que se cometan en contra de esta ley, entre otros aspectos de la fiscalización y control de los gastos electorales ${ }^{168}$.

Sin embargo, los Partidos políticos sancionados consideraron que el SE solo está facultado para practicar un examen formal del movimiento contable, toda vez que el Título $V$ de dicha Ley que trata el Financiamiento de los Partidos Políticos, ${ }^{169}$ faculta al Director del Servicio Electoral para solicitar, a lo menos una vez en cada año, los libros y documentación contable de los partidos políticos con el objeto de revisar e inspeccionar dichos antecedentes. Lo que tiene como finalidad vigilar el cumplimiento de las normas de financiamiento y contabilidad de los Partidos.

Pero esto no limita al Servicio Electoral el poder verificar la existencia de la contabilidad, sin hacer un análisis de la forma en que esta es llevada, lo que no significa calificar de apropiados o inapropiados los gastos hechos por los Partidos Políticos ${ }^{170}$. Por lo que pasaremos a señalar cuáles fueron los motivos y sanciones más comunes que conoció el TCE como Tribunal de alzada, ante la inconformidad de los sancionados.

Con la nueva legislación en materia de gastos electorales, se localizaron varias sentencias para dar incumplimiento al artículo 31 letra c) de la Ley sobre Transparencia, Límite y Control del Financiamiento Electoral, que establece como obligación de los Administradores Electorales la de "Remitir al Administrador General Electoral del respectivo partido político la información contable y la documentación relativa a los ingresos y gastos electorales de la candidatura a su cargo, dentro del plazo de diez días contado desde la fecha de la elección correspondiente" ${ }^{\prime 171}$.

Asimismo, la ley de gasto electoral señala en su artículo 33 letra c) al referirse a las obligaciones de los Administradores Electorales Generales: "c) Remitir al Director del Servicio Electoral, en la forma y plazo establecidos en la presente ley, la información contable y la documentación relativa a los ingresos y gastos electorales del respectivo partido político, como asimismo las correspondientes a la totalidad

\footnotetext{
169 Artículo 34, inciso $3^{\circ}$.

170 Sentencias rol 2 y 3-91, 2-94 y 39-97.

171 Sentencia ro133-05.
} 
de las candidaturas inscritas en representación del partido".

En este caso se revocó la sentencia del SERVEL, porque el TCE estimó que el responsable de presentar el informe contable de los gastos electorales era el Administrador Electoral General del Partido Político y no el Administrador Electoral del candidato.

Las sanciones impuestas por el SE a los administradores electorales por el manejo de los recursos financieros fueron principalmente por dos motivos: 1. La responsabilidad tanto del Administrador General como del Administrador Electoral de llevar un registro contable ${ }^{172}$ y 2 . Haber informado un gasto que no se ajustó a los documentos o comprobantes acompañados y no presentar en tiempo este informe (hasta 30 días después de la elección) ${ }^{173}$.

Estas disposiciones se aplicaron a los administradores electorales, por ejemplo, se sancionó a un administrador electoral, porque no precisó en la contabilidad de ingresos el origen de los mismos con una multa equivalente a 50 UTM (cincuenta Unidades Tributarias Mensuales, infracción a los artículos 38 y 41 de la Ley de Gasto y Control Electoral) ${ }^{174}$. En otros casos, la multa fue equivalente al doble de la parte no declarada de los gastos electorales que no fueron justificados ${ }^{175}$.

En otro asunto particular, el SE decidió imponer multa, porque en la cuenta rendida por el Administrador General de una candidatura independiente no aparecieron registrados otros ingresos para financiar gastos electorales por ciento cincuenta y tres mil doscientos setenta y dos pesos $(\$ 153.272)^{176}$. Como hemos anotado, el TCE ha tenido una conducta legalista, por lo que en este negocio decidió confirmar la sanción elaborada por el SE. Sin embargo, los votos disidentes de los Ministros Pérez y Luengo acogieron la reclamación, con el propósito de re-

\footnotetext{
172 Artículo 38 de la Ley de Gasto Electoral.

173 Artículo 41 de la Ley de Gasto Electoral.

174 Sentencia rol 95-05.

175 Sentencia rol 96-05.

176 Sentencia rol 98-05.
}

vocar la resolución, (que decidió aplicar una multa de trescientos seis mil quinientos cuarenta y cuatro pesos ( $\$ 306.544)$ por no haber justificado aportes para financiar los gastos, en exceso de los cuarenta mil pesos $(\$ 40.000)$. Los ministros en comento estimaron que la campaña electoral de la candidata a concejal fue austera, ya que el total de gastos electorales efectuados en dicha campaña fue de ciento noventa y tres mil doscientos setenta y dos pesos ( $\$ 193.272)$ y que los gastos que se han considerado no justificados, han sido financiados con el propio peculio de la candidata, más aún considerando, que se trataba de cantidades de poca monta.

Existen varios casos en que el SE no presentó la apelación en el plazo legal que establece el TCE, ocasión que se aprovechó en diversas oportunidades para que el sancionado señalara al Tribunal el vencimiento del término para responder del $\mathrm{SE}$, con base en el artículo 42 de la Ley sobre Transparencia, Límite y Control del Gasto Electoral que dispone: "El Director del Servicio Electoral deberá pronunciarse respecto de la cuenta de ingresos y gastos dentro de los treinta días siguientes de expirado el plazo a que se refiere el inciso primero del artículo anterior. $\mathrm{Si}$ el Director del Servicio estimare necesario un examen más acabado de los antecedentes presentados, podrá prorrogar dicho plazo una vez y hasta por un máximo de quince días. Vencidos estos plazos, sin que el Director del Servicio se hubiere pronunciado sobre la cuenta, esta se entenderá aprobada", por lo que el TCE declaró que se dejaba sin efecto la resolución del SE ${ }^{177}$.

En este tema nuevamente encontramos la rigidez del TCE al momento de sancionar. Por ejemplo, la cuestión de no presentar en tiempo la apelación, era motivo para su inadmisibilidad ${ }^{178}$ y en otros casos declararon la inadmisibilidad porque la apelación no cumplía el requisito de la firma ${ }^{179}$.

A continuación se presentarán las impugnaciones de los candidatos independientes y los partidos po-

\footnotetext{
177 Sentencia rol 110-05.

178 Sentencia rol 15-05.

179 Sentencia rol 31-05.
} 
líticos, por la distribución del tiempo de televisión abierta que contempla la ley de Votaciones Populares y Escrutinios.

\section{DISTRIBUCIÓN DEL TIEMPO ELECTORAL}

En Chile está prohibida la contratación de publicidad electoral en televisión abierta a los candidatos y partidos políticos. Por lo que el Estado distribuye cierto tiempo a través del Consejo Nacional de Televisión (CNTV) entre los Pero esta repartición contendientes electorales, no les pareció para que puedan realizar proporcional y su publicidad de manera menos equitativa a gratuita y poder presentar muchos. sus ofertas políticas a la ciudadanía. Sin embargo, esta distribución ha llevado a la insatisfacción por los tiempos entregados a los competidores electorales. Lo que ha sido motivo de inconformidad por los candidatos independientes $y$ varios partidos políticos ante el TCE.

El artículo 31 de la ley de votaciones señala que los canales de televisión abierta deben destinar determinados minutos diarios de sus transmisiones a propaganda electoral en los casos de elección de Presidente de la República, de Diputados y Senadores, y en materia de plebiscitos. Pero cuando corresponda efectuar elecciones conjuntas, esos canales destinarán -también en forma gratuita- cuarenta minutos diarios a esa propaganda, los que se distribuirán en veinte minutos para la elección de Presidente de la República y veinte minutos para la elección de Diputados y Senadores.

El mismo artículo 31 en su inciso tercero precisa que para la elección de Presidente de la República, el tiempo se distribuirá en partes iguales para cada uno de los candidatos.

También el artículo 13 transitorio de esta ley señala que en el caso de las primeras elecciones de Diputados y Senadores el tiempo que debían destinar los canales de televisión de libre recepción para propaganda electoral, correspondería a las listas en proporción al número de regiones en que estuvieren legalmente constituidos el partido o partidos pac- tantes. Al conjunto de candidaturas independientes corresponderá un tiempo equivalente al del partido político legalmente constituido en el menor número de regiones, el que se distribuirá entre ellos por iguales partes ${ }^{180}$.

Por lo que el TCE, al estudiar el tema de la propaganda y publicidad electoral, reconoció el derecho de los partidos y conglomerados políticos para publicitar sus ofertas políticas con el objetivo de inducir a los electores a emitir su voto por determinados candidatos o al apoyo de alguna de las proposiciones sometidas a plebiscito; que esa noticia es la que debe transmitirse, encuadrándola dentro del tiempo que, con esa finalidad, la ley otorga para una difusión gratuita a través de los canales de televisión de libre recepción; y, dentro de la disponibilidad que así se concede, el Consejo ha debido fijar los cupos de tiempo en consideración a las posibilidades del servicio televisivo, acogido a la experiencia allegada en comicios anteriores y de acuerdo con la proporción que -en esta oportunidad-corresponde a cada sector político, de manera que todos ellos logren disponer cumplidamente la cuota que la ley les brinda ${ }^{181}$.

Como podemos observar, la distribución del tiempo entre los candidatos es fundamental en sus campañas políticas. Pero esta repartición no les pareció proporcional y menos equitativa a muchos. Por lo que en al año 2005 Ricardo Fernández Sanhueza se presentó como Presidente de la "Alianza Nacional de los Independientes" y por el "Partido de Acción Regionalista" e interpuso el recurso de apelación ante el TRICEL contra el fallo del Consejo Nacional de Televisión, publicado el diecisiete de octubre de dos mil cinco que establecía la distribución del tiempo para la propaganda electoral gratuita por televisión para las elecciones presidenciales y parlamentarias $^{182}$.

\footnotetext{
180 Esto es relevante para la sentencia rol 92-2005, que analizaremos más adelante.

181 Sentencia rol 100-89.

182 Sentencia rol 92-2005.
} 
El objeto de esta apelación era someter a decisión del TCE si la asignación de los tiempos de propaganda electoral gratuita emitida por los canales de televisión de libre recepción, hecha por el Consejo Nacional de Televisión, era justa o no.

El tiempo con el que cuentan los candidatos independientes se encuentra establecido en el inciso quinto del artículo 31 de la Ley de Votaciones, que determina que al conjunto de las candidaturas independientes corresponde un tiempo equivalente al del partido político que hubiere obtenido menos sufragios en la última elección, mismo que se distribuirá entre ellos por iguales partes ${ }^{183}$.

En este caso, el TCE declaró inadmisible el recurso presentado por la falta de representación de Ricardo Fernández Sanhueza, en cuanto compareció por el "Partido de Acción Regionalista". Además, confirmó el acuerdo del Consejo Nacional de Televisión, que distribuyó el tiempo para la propaganda electoral gratuita por los canales de televisión de libre recepción.

En esta sentencia se adjuntó el voto concurrente del Ministro Juica por la confirmatoria de la sentencia en lo principal, pero con declaración de ordenar al CNTV para que adoptara las medidas y procedimientos a fin de asegurar que en los programas de opinión y de debate político que se emitieran por cualquier canal de televisión se respetara el principio de igualdad y de pluralismo, solicitando se otorgara más tiempo de la franja electoral a los candidatos independientes ${ }^{184}$ :

"El Consejo Nacional de Televisión, conforme a sus facultades constitucionales y legales, debe adoptar las medidas para asegurar un trato mínimo equitativo entre los distintos candidatos de manera que la población destinataria se ilustre adecuadamente de los postulantes al Congreso Nacional, sean estos militantes de partidos políticos o independientes, y así quede informada para participar en el proceso

183 En este caso fue el Partido Liberal con 3.745 votos.

184 Esto con base en el artículo 18 constitucional, que establece plena igualdad entre los competidores electorales. eleccionario de que se trate. Que al fijar dicho organismo el tiempo de propaganda electoral para el Pacto Fuerza Regional de Independientes y los independientes en general en dos y un segundo, respectivamente, excede con mucho el criterio y prudencia que es menester considerar a fin de que los independientes puedan, dentro del trato igualitario y de observancia al principio de pluralismo político, exponer las ideas que justifiquen, ante la opinión pública, su programa político para el cargo al que aspira y, en este sentido, el previniente fue de opinión de considerar como un mínimo aceptable para estos fines un tiempo no inferior a veinte segundos de difusión propagandística para cualquier candidatura y sobre tal tiempo mínimo y, para los demás, efectuar el cálculo que exige la ley" ${ }^{\prime 185}$.

\section{CONCLUSIONES}

- Nuestro punto de salida es considerar que: "las elecciones son la fuente de legitimidad para los gobiernos y posibilidad para que los ciudadanos opten por diferentes ofertas" ${ }^{\prime 186}$. Por lo que el Tribunal es responsable de garantizar a los ciudadanos el respeto de su voto y al mismo tiempo debe calificar que las elecciones se hayan celebrado conforme al marco jurídico:

"El objetivo de la justicia electoral es dotar a partidos políticos y ciudadanos de elementos certeros e institucionales para que todos los conflictos electorales encuentren una solución legal. La creación de instancias encargadas de la revisión de los actos de las autoridades y de la persecución de ilícitos constituye una de las anclas básicas no solo de la legalidad, sino de la legitimidad de los

185 Incisos E y G del voto concurrente del Ministro Juica de la Sentencia rol 92-2005.

186 Becerra, Ricardo, La reforma electoral de 1996, Ed. FCE México, 1997, p. 18. 
procesos electorales. De igual manera, la legitimidad de los comicios constituye, a su vez, el fundamento de las instituciones públicas en un Estado democrático"187.

- El sistema jurisdiccional electoral chileno reposa sobre la fidelidad de los procedimientos y formas que el legislador ha dispuesto, circunstancia que resulta esencial para mantener las bases de su sistema democrático, por cuanto legitima tanto el proceso electoral de que se trate como el resultado oficial al que se arribe como la expresión libre e informada del electorado. ${ }^{188}$

- Después de revisar la jurisprudencia emitida por el Tribunal Calificador de Elecciones, podemos diagnosticar cómo ha sido el comportamiento de esta institución. En primer lugar detectamos que el sistema jurisdiccional electoral chileno utiliza el modelo democrático mínimo, esto significa que este Tribunal se ha avocado de manera exclusiva las cuestiones procedimentales de las elecciones, sin ver aspectos como los derechos de los ciudadanos o de los afiliados de los partidos políticos. Es más, no ha definido el sentido y alcance del sistema democrático en el sistema político chileno.

Por otro lado, vemos que el TCE al utilizar el modelo democrático procedimental utiliza de manera primaria la legislación electoral y secundariamente los principios constitucionales de igualdad y publicidad establecidos en la Constitución.

La interpretación gramatical se comprende como aquella que se hace con "el sentido de la ley con base en el significado de los términos empleados en su redacción"189. Este sistema de interpretación y aplicación de las normas ha sido conservador del mismo, ${ }^{190}$ así como lo absurdo de un método que pretende

\footnotetext{
187 Woldenberg, José, "Orígenes, función y perspectivas del TEPJF", en Testimonios sobre el desempeño del TEPJFy su contribución al desarrollo político democrático de México, Ed. TEPJF, México, 2003, p. 354.

188 Sentencia rol 12-2009.

189 Nieto, Santiago, Interpretación y argumentación jurídicas en materia electoral, op. cit., p. 41.

190 Artículo 20 Código Civil Chileno.
}

la existencia de un solo significado de los términos, "cuando la realidad nos dice que el vocabulario frecuentemente posee un carácter polisémico en el lenguaje común"191.

Santiago Nieto considera que este mecanismo es el más simple para interpretar la ley. "se sostiene que el intérprete, mediante las reglas gramaticales, conoce el significado correcto de las frases empleadas por la legislación"192.

Este criterio para interpretar la norma se refiere a que se busca el significado de los términos o de las palabras y dilucidar la estructura gramatical de la frase y el propio texto nos establece su alcance y significa por el alcance por la semántica y sintaxis del precepto. Esto no es una mera operación mecánica, sino que las palabras aisladas o por sí solas no tienen un significado preciso, sino que es preciso referirlas al co-texto dentro de la frase y de ahí al contexto real que se estudia o se trata de interpretar y circunstancias concretas que evidencian el motivo y el propósito del tema de estudio. Muy pocas veces el Tribunal hace uso de doctrina y en muy pocas ocasiones utiliza sentencias de la Corte Suprema de Justicia o del Tribunal Constitucional. Lo que significa que menoscaban otras fuentes de interpretación, además de que al esclarecer el sentido de la ley no toman en consideración factores como el factor político y el social.

- Asimismo, al analizar las sentencias del TRICEL notamos que realiza una aplicación de la justicia muy legalista. Este mecanismo de exégesis se puede entender como "la irrestricta observancia de la ley por parte de las autoridades encargadas de aplicarla y de los ciudadanos a los que va dirigida. El legalismo persigue la aplicación mecánica de la ley, toda vez que la seguridad jurídica fuerte es su máximo valor" $^{\prime 193}$

\footnotetext{
Nieto Santiago, Interpretación y argumentación jurídicas en materia electoral, op. cit., p. 301

192 ĺdem, p. 42.

193 Nieto, Santiago, Interpretación y argumentación jurídicas en materia electoral, op. cit., p. 54.
} 
Esta aplicación de la norma denota la excesiva utilización del sentido literal de cada término o concepto, por ejemplo, me llamó la atención que en diversas ocasiones no juzgaban un asunto por no tener competencia basado en la Constitución o en ley; pero me parece contradictorio que en un Estado de derecho, se soslaye la impartición de justicia por anteponer el principio de legalidad, y considerar que si no está dentro de sus facultades juzgar algún caso, no se resuelva. Entonces qué pasa con los justiciables y su solicitud de administración de justicia, pues nada; pues aunque se violen sus derechos ciudadanos, hay que recordar que las sentencias del TCE son definitivas e inapelables.

Otro ejemplo, lo tenemos cuando en los casos de diferencias al interior de los partidos políticos, ha declarado que no tiene competencia por ley. También, debo señalar que el TCE ha declarado que se debe manifestar exactamente los agravios recibidos; al calificar, verifica que la demanda contenga todos los requisitos de forma, desechando el recurso ante tal incumplimiento, pudiendo haber prevenido a la parte de sus errores, imprecisiones o faltantes en la demanda de justicia; otro caso que se debe desahogar en el recurso, es cómo le afectaron los actos expuestos y adjuntar las pruebas que puedan advertir esa supuesta violación, etc. Por lo que el TRICEL ha decidido que si no se cumplen cabalmente los requisitos, el recurso es desechado o calificado como improcedente.

- La jurisprudencia electoral no tiene carácter obligatorio, solo es aplicable al caso y crea un referente tanto para el Tribunal Electoral como para los actores políticos. Tampoco ha señalado el significado y alcance de los derechos políticos, pues a la fecha no los ha definido en su jurisprudencia. De hecho, a diferencia de varios países ni siquiera ha señalado o considerado a los derechos ciudadanos como Derechos Humanos. ${ }^{194}$

- La jurisprudencia del TRICEL en relación con los derechos políticos ha sido casi nula y excesivamen-

194 Vid, Moia, Luis Ángel, "Los derechos políticos como Derechos Humanos", en Revista del Instituto Interamericano de Derechos Humanos, No. 45, Costa Rica, 2007, pp. 353-428. te deferente a las decisiones de los poderes políticos, pues en contadísimas ocasiones han fiscalizado debidamente las elecciones ante denuncias de fraude.

- Un elemento que debemos destacar dentro de la actuación del TCE es el de la conservación de los actos electorales. Esto significa que no cualquier infracción deberá anular la votación de una mesa, de un distrito o de una región, sino que deberá tomarse en consideración para la anulación de la votación el cúmulo de infracciones, y segundo, si estas supuestas infracciones tendrían un efecto modificatorio en el resultado general de las elecciones, pues si la diferencia entre los principales candidatos es mínima, estos votos harían la diferencia para designar al candidato ganador.

- El mayor impacto de las sentencias del TCE se observa más en los casos de destitución de autoridades municipales, pues al no ser precisamente una función que tenga relación directa con los derechos políticos o la calificación de los procesos electorales esta destitución la decide el TCE. En estos casos se han removido varias autoridades ante el incumplimiento de sus funciones.

La remoción de un Alcalde o Concejal no solo afecta a la primera autoridad municipal en su persona, sino que también reviste la innegable connotación de un desprestigio de la función pública ante la ciudadanía, que espera de sus autoridades una conducta apegada irrestrictamente al Derecho y a los principios de probidad, eficiencia y eficacia administrativas exigibles a todas las autoridades y funcionarios de la Administración del Estado por el ordenamiento jurídico.

El grave y notable abandono de deberes y la falta de probidad son las principales causales para la destitución de autoridades municipales en Chile. Pero vemos cómo la jurisprudencia ante el silencio de la Ley ha interpretado al "notable abandono de deberes" y ha juzgado de una forma discrecional varios casos en que consideró que sí hubo un "notable" o en qué abandono de deberes y la falta de probidad, son las principales causales

para la destitución

de autoridades

municipales en Chile. 
casos no fue "notable" y si causo o no perjuicios a la administración municipal.

Pero no han establecido un criterio fijo, pues al valorar las pruebas como jurado han señalado en varios casos que no ha sido "notable" o "grave" el abandono de sus deberes, y que se trata de cuestiones que se pueden enmendar o de faltas menores que no ameritan la solicitud de destitución.

Existe sin duda un elemento subjetivo al calificar a las autoridades municipales, cuando se cree que hubo un notable abandono de deberes. Al revisar las sentencias del Tribunal Calificador de Elecciones hay diversos criterios jurisdiccionales (dependiendo del caso) en que han juzgado sin una constante, originando que sea reevaluada la conducta del Alcalde o Concejal, por un órgano de naturaleza electoral y no por uno propiamente judicial, para evaluar conductas políticas y/o administrativas. Pues como señala Jesús Orozco: "la utilización de expresiones deliberadamente ambiguas, vagas, cláusulas abiertas, conceptos indeterminados, y demás, por el legislador o constituyente, producen un efecto indeseable que la seguridad jurídica exige minimizar a saber: una incertidumbre sobre si determinado hecho es subsumible en una norma"195.

- Uno de los puntos críticos que encontramos es la valoración de las pruebas por parte del TRICEL, por que si bien la Ley faculta al Tribunal para "valorar como jurado y sentenciar con fundamentos jurídicos", esto no es posible para un Tribunal que juzga profesionalmente; sus principios rectores deben fundamentarse en ser un órgano contencioso, en donde todos sus fallos se apeguen a la normativa legal y no a decisiones como si fueran un jurado ${ }^{196}$.

195 Orozco Henríquez, Jesús, Justicia electoral y garantismo jurídico, op. cit., p. 248.

196 Estamos hablando de un elemento que es parte de dos sistemas de administración de justicia. Pues en los modelos Continentales no hay jurado y si valora conforme a las pruebas ubicadas en el expediente. Mientras que en el sistema Anglo-americano el jurado es una parte fundamental y puede valorar las pruebas sin ninguna regla o sujeción. Damaska, Mirjan R., The faces of justice and state authority, Ed. Yale University Press, USA, 1986, p. 91.
- En cuanto al rubro de la anulación de elecciones en Chile. Tenemos que desde la reinstauración de la democracia en Chile en el año de 1989, solamente en una ocasión se han revocado los resultados de toda una elección. Esto sucedió en la elección de Alcalde en la comuna de Talcahuano, en el año 2004.

La invalidación de esta elección se debió al cúmulo de infracciones a las normas contenidas en la ley de votaciones y escrutinios populares (entre ellos el comportamiento irregular de las personas responsables de las mesas receptoras, las contradicciones entre los votos emitidos y los registrados, entre otras irregularidades).

\section{REFERENCIAS BIBLIOGRÁFICAS}

Becerra, Ricardo, Salazar, Pedro y Woldenberg, José, La Reforma de 1996, Ed. FCE, México, 1997.

Castillo González, Leonel, Reflexiones temáticas de derecho electoral, Ed.TEPJF, México, 2008.

Damaska, Mirjan R., The faces of justice and state authority, Ed. Yale University Press, USA, 1986.

González Roura, Felipe, "Justicia Electoral y resolución de conflictos: Quince años de experiencia Argentina" en Revista Jurídica Jalisciense, México, 2005.

Moia, Luis Ángel, "Los derechos políticos como derechos humanos", en Revista del Instituto Interamericano de Derechos Humanos, No. 45, Costa Rica, 2007.

Nieto, Santiago, Interpretación y argumentación jurídicas, Ed. UNAM, México, 2006.

Ojesto Martínez Porcayo, José Fernando, "Jurisprudencia electoral, aporte para el fortalecimiento de la jurisprudencia" en Revista de Derecho Electoral, Número 8, Costa Rica, 2009.

Orozco Henríquez, Jesús, Justicia electoral y garantismo jurídico, Ed. Porrúa, México, 2006.

Rosales García, Carlos Manuel, "Análisis crítico del sistema de remoción de autoridades edilicias en el sistema electoral chileno", Revista de derecho Electoral, número 8, Costa Rica, 2009. 
Valladares, Carmen Gloria, "sobre lo contencioso electoral y la jurisprudencia electoral en Chile", en El contencioso y la jurisprudencia electorales en derecho comparado, Ed.TEPJF, México, 2008.

Sobrado González, Luis Antonio, "Tendencia de la justicia electoral latinoamericana y sus desafíos democráticos", en Revista de Ciencias Jurídicas, Número 109, enero-abril, Costa Rica, 2006.

Sobrado González, Luis Antonio, "La jurisprudencia electoral como factor de profundización democrática en América Latina", en Revista de Derecho Electoral, Número 7, Costa Rica, 2009.
TEPJF, El sistema mexicano de justicia electoral, Ed. TEPJF, México, 2003.

Woldenberg, José, "Orígenes, función y perspectivas del TEPJF", en Testimonios sobre el desempeño del TEPJF, Ed.TEPJF, México, 2006.

UNAM. Instituto de Investigaciones Jurídicas. Diccionario Jurídico Mexicano, Tomo III, Editorial Porrúa, 11ª Edición, México, 1998.

Legislación electoral chilena.

Jurisprudencia electoral chilena producida entre 1989 y 2007. 